\title{
Characteristics and properties
} of nano- $\mathrm{LiCoO}_{2}$ synthesized by pre-organized single source precursors: Li-ion diffusivity, electrochemistry and biological assessment

\author{
Jean-Pierre Brog ${ }^{1}$, Aurélien Crochet ${ }^{2}$, Joël Seydoux ${ }^{1}$, Martin J. D. Clift ${ }^{3}$,, Benoît Baichette ${ }^{1}$, \\ Sivarajakumar Maharajan ${ }^{1}$, Hana Barosova ${ }^{3}$, Pierre Brodard ${ }^{4}$, Mariana Spodaryk ${ }^{5}$, Andreas Züttel ${ }^{5}$ (D), \\ Barbara Rothen-Rutishauser ${ }^{3}$ (D) Nam Hee Kwon ${ }^{1 *}$ (D) and Katharina M. Fromm ${ }^{1 *}$ (D)
}

\begin{abstract}
Background: $\mathrm{LiCOO}_{2}$ is one of the most used cathode materials in Li-ion batteries. Its conventional synthesis requires high temperature $\left(>800^{\circ} \mathrm{C}\right)$ and long heating time $(>24 \mathrm{~h})$ to obtain the micronscale rhombohedral layered hightemperature phase of $\mathrm{LiCOO}_{2}$ (HT-LCO). Nanoscale HT-LCO is of interest to improve the battery performance as the lithium $\left(\mathrm{Li}^{+}\right)$ion pathway is expected to be shorter in nanoparticles as compared to micron sized ones. Since batteries typically get recycled, the exposure to nanoparticles during this process needs to be evaluated.

Results: Several new single source precursors containing lithium $\left(\mathrm{Li}^{+}\right)$and cobalt $\left(\mathrm{Co}^{2+}\right)$ ions, based on alkoxides and aryloxides have been structurally characterized and were thermally transformed into nanoscale HT-LCO at $450{ }^{\circ} \mathrm{C}$ within few hours. The size of the nanoparticles depends on the precursor, determining the electrochemical performance. The Li-ion diffusion coefficients of our $\mathrm{LiCOO}_{2}$ nanoparticles improved at least by a factor of 10 compared to commercial one, while showing good reversibility upon charging and discharging. The hazard of occupational exposure to nanoparticles during battery recycling was investigated with an in vitro multicellular lung model.

Conclusions: Our heterobimetallic single source precursors allow to dramatically reduce the production temperature and time for $\mathrm{HT}$-LCO. The obtained nanoparticles of $\mathrm{LiCOO}_{2}$ have faster kinetics for $\mathrm{Li}^{+}$insertion/extraction compared to microparticles. Overall, nano-sized $\mathrm{LiCOO}_{2}$ particles indicate a lower cytotoxic and (pro-)inflammogenic potential in vitro compared to their micron-sized counterparts. However, nanoparticles aggregate in air and behave partially like microparticles.
\end{abstract}

Keywords: Single source precursors, Nano-LiCoO ${ }_{2} \mathrm{Li}^{+}$Diffusion coefficient, Li-ion batteries, Nanoparticle hazard

\section{Background}

Lithium cobalt oxide $\mathrm{LiCoO}_{2}$ has been the most commonly used cathode material in rechargeable Li-ion batteries since Goodenough first introduced the reversible reaction of Li-ions in the structure [1]. The structures of $\mathrm{Li}_{1-\mathrm{x}} \mathrm{CoO}_{2}$ have been extensively studied as a function of

\footnotetext{
*Correspondence: namhee.kwon@unifr.ch; katharina.fromm@unifr.ch 1 Department of Chemistry, University of Fribourg, Chemin du Musée 9, 1700 Fribourg, Switzerland

Full list of author information is available at the end of the article
}

lithium de-intercalation, leading to several phase transformations from rhombohedral with $0.06<\mathrm{x}<0.25[2-$ $5]$, via monoclinic with $x=0.5$ [2,3], to hexagonal for $0.66<\mathrm{x}<0.83[6,7]$, and a second hexagonal phase, O1, for $0.88<\mathrm{x}<1[6-8]$.

The layered structure of lithiated $\mathrm{LiCoO}_{2}$ exhibits two crystal structures depending on the temperature during synthesis and the preparation method. $\mathrm{LiCoO}_{2}$ produced at low temperature $\left(\sim 400{ }^{\circ} \mathrm{C}\right)(\mathrm{LT}-\mathrm{LCO})$ has a cubic spinel structure with the space group $F \mathrm{~d} 3 \mathrm{~m}[9,10]$ while the phase synthesized at high temperature $\left(>850{ }^{\circ} \mathrm{C}\right.$, 
HT-LCO) has a rhombohedral layered structure [11]. LTLCO shows a large hysteresis between the intercalation and de-intercalation of lithium ions [12-14], which is due to the mixing of $\mathrm{Co}^{3+}$ and $\mathrm{Li}^{+}$in the structure, preventing the formation of layered pathways for Li-ion diffusion. The material is therefore calcined at higher temperature to yield HT-LCO, which possesses alternating planes of $\mathrm{Co}^{3+}$ and $\mathrm{Li}^{+}$cations in the hexagonal ABCABC oxygen packing [15], providing superior electrochemical properties in Li-ion batteries [16].

Industrially, two starting materials, typically $\mathrm{Li}_{2} \mathrm{CO}_{3}$ and $\mathrm{Co}_{3} \mathrm{O}_{4}$, are heated in a two-step process to yield first at a temperature of $<600{ }^{\circ} \mathrm{C}$ for $24 \mathrm{~h}$ under $\mathrm{O}_{2}$ the LT-LCO. A second calcination step at $900{ }^{\circ} \mathrm{C}$ for $>12 \mathrm{~h}$ under $\mathrm{O}_{2}$ [17] yields the HT-LCO [18-20]. Such a prolonged calcination process at high temperature causes however coarsening of the particles and evaporation of lithium [21]. Various synthetic methods have thus been investigated to avoid the high temperature process, with the aim to obtain the rhombohedral layered structure of HT-LCO, e.g. sol-gel [22-25], hydrothermal [26], or precipitation [16]. However, low temperature syntheses formed mostly the cubic spinel LT- $\mathrm{LiCoO}_{2}$, which is not favorable for $\mathrm{Li}^{+}$insertion/extraction. Thus, calcination at high temperature $>800^{\circ} \mathrm{C}$ was always required in a second step to use the so-produced material in Li-ion battery cathodes [16].

Another access to the layered structure of HT-LCO uses metal-organic single source precursors based on alkoxides or aryloxides, in which the metal ions are already preorganized. Indeed, the synthesis of heterobimetallic alkoxides and/or aryloxides can provide a facile route for obtaining soluble, volatile, and generally monomeric species, that can thus serve as valuable precursors for making metal oxides under rather mild conditions [27-36]. For example, Buzzeo published homoleptic cobalt phenolate compounds of the type $\mathrm{K}_{2}\left[\mathrm{Co}(\mathrm{OAr})_{4}\right]$ $\left(\mathrm{OAr}=\mathrm{OC}_{6} \mathrm{~F}_{5}^{-}\right.$or $\left.3,5-\mathrm{OC}_{6} \mathrm{H}_{3}\left(\mathrm{CF}_{3}\right)_{2}^{-}\right)$, in which the effect of fluorination of phenoxide on (K18C6) ${ }_{2}\left[\mathrm{Co}(\mathrm{OAr})_{4}\right]$ is highlighted [37]. Boyle et al. published lithium cobalt double aryloxide compounds obtained from $\mathrm{LiN}\left(\mathrm{SiMe}_{3}\right)_{2}$, $\mathrm{Co}\left(\mathrm{N}\left(\mathrm{SiMe}_{3}\right)_{2}\right)_{2}$ in THF and subsequent addition of an aryl alcohol. They obtained nanoparticles of $\mathrm{LiCoO}_{2}$ by thin film formation [38], but did not characterize them electrochemically. Nanoparticles of HT-LCO have the advantage to offer shorter diffusion lengths for the Liions as compared to the commercial, micron-sized particles from which only $\sim 50 \%$ of Li-ions can be used [ 26 , $35]$. On the other hand, since batteries are typically also shredded upon recycling, the use of nanomaterials in batteries might present a certain danger, which requires a risk management for new materials.
In this context, we present here new molecular precursors using simple ligands such as phenoxide and alkoxides with a low amount of carbon atoms that can produce nano-HT-LCO at quite low temperature. We have tested the new materials for their electrochemical properties in cathodes and their Li-ion diffusion coefficients were determined. In order to evaluate possible material hazards, the nanoparticles of HT-LCO were exposed directly at the air-liquid interface (ALI) using a well-established in vitro multicellular lung model [39]. The lung was chosen as an experimental tissue, since it can be considered by far the most important portal of entry for aerosolized nanoparticles into the human body [40-46]. Although various aspects of nanoparticles toxicity have already been described and studied in the recent literature, almost no studies were carried out in the domain of battery cathode nanoparticles.

\section{Methods}

\section{Materials and reagents}

Cobalt chloride $\left(\mathrm{CoCl}_{2}\right)$ (dry or hydrated with two $\mathrm{H}_{2} \mathrm{O}$ ), lithium phenoxide ( $\mathrm{LiOPh}$ ) in tetrahydrofuran (THF), lithium iso-propoxide ( $\mathrm{LiO}^{i} \mathrm{Pr}$ ) in THF, ethanol (technical grade and analytical grade), tetramethylethylenediamine (TMEDA), dioxane, dimethoxyethane (DME), pyridine (Py), heptane and micron-sized $\mathrm{HT}-\mathrm{LiCoO}_{2}$ were purchased from Sigma-Aldrich (Switzerland). Lithium tertbutoxide $\left(\mathrm{LiO}^{t} \mathrm{Bu}\right)$ in THF, lithium methoxide (LiOMe) in methanol, lithium ethoxide (LiOEt) in THF and THF (dry and over molecular sieves) were purchased from Acros Organics (Belgium). Deionized water was produced in house by double distillation.

\section{Synthesis of bimetallic complexes [47]}

All experiments were carried out under an inert argon atmosphere, using Schlenk techniques [48]. All solvents were bought dried and were stored over molecular sieve. The elemental analysis of the compounds turned out to be difficult to obtain due to the instability of most compounds in air, based on the loss of (coordinated) solvent.

The compounds $\left[\mathrm{Co}(\mathrm{OPh})_{4} \mathrm{Li}_{2}(\mathrm{THF})_{4}\right](\mathbf{1}),\left[\mathrm{Co}(\mathrm{OPh})_{4} \mathrm{Li}_{2}\right.$ (THF) $\left.{ }_{4}\right] \cdot \operatorname{THF}(\mathbf{2}),\left[\mathrm{Co}(\mathrm{OPh})_{4} \mathrm{Li}_{2}(\mathrm{THF})_{2}\left(\mathrm{H}_{2} \mathrm{O}\right)(\mathrm{THF})_{2}\right]_{2}(\mathbf{3})$, $\left[\mathrm{Co}(\mathrm{OPh})_{4} \mathrm{Li}_{2}(\mathrm{TMEDA})_{2}\right](\mathbf{4}),\left[\mathrm{Co}(\mathrm{OPh})_{4} \mathrm{Li}_{2}(\text { dioxane })_{2}\right]_{\mathrm{n}}$ (5), $\left[\mathrm{Co}(\mathrm{OPh})_{4} \mathrm{Li}_{2}(\mathrm{DME})_{2}\right]$ (6), $\left[\mathrm{Co}(\mathrm{OPh})_{4} \mathrm{Li}_{2}(\mathrm{Py})_{4}\right]$ (7), $\left[\mathrm{Co}_{2}\left(\mathrm{O}^{t} \mathrm{Bu}\right)_{6} \mathrm{Li}_{4}(\mathrm{THF})_{2}\right](\mathbf{8}),\left[\mathrm{Co}_{2}\left(\mathrm{O}^{t} \mathrm{Bu}\right)_{2}(\mathrm{OPh})_{4} \mathrm{Li}_{2}(\mathrm{THF})_{4}\right]$ (9), $\left[\mathrm{Co}_{2}\left(\mathrm{O}^{i} \mathrm{Pr}\right)_{6} \mathrm{Li}_{2}(\mathrm{THF})_{2}\right](\mathbf{1 0}),\left[\mathrm{Co}_{2}(\mathrm{OEt})_{12} \mathrm{Li}_{8}(\mathrm{THF})_{8-10}\right]$ (11), and $\left[\mathrm{Co}_{2}(\mathrm{OMe})_{6} \mathrm{Li}_{2}(\mathrm{THF})_{2}(\mathrm{MeOH})_{2}\right](\mathbf{1 2})$ were synthesized using $\mathrm{CoCl}_{2}$ as starting material and reacting it with the corresponding lithium aryloxide or alkoxide. In a typical reaction procedure, dried $\mathrm{CoCl}_{2}$ is dissolved in dry THF under heating to reflux. After stirring for $30 \mathrm{~min}$, aliquots of $\mathrm{LiOR}\left(\mathrm{R}=\mathrm{Ph},{ }^{t} \mathrm{Bu},{ }^{i} \mathrm{Pr}, \mathrm{Et}, \mathrm{Me}\right)$ 
are added. The mixture is heated to reflux, stirred during $30 \mathrm{~min}$ and then concentrated. Layering the concentrated solution with a non-solvent, respectively solvent exchange lead to single crystalline material for compounds 1-5 and 9, while powders were obtained for 6-8 and 10-12. Table 1 resumes the reaction conditions for all compounds, with detailed synthesis protocols and IRanalyses given in the Additional file 1: Text 1.

\section{Calcination to $\mathrm{LiCoO}_{2}$}

Among the so obtained precursors, compounds 1, 8-12 were heated up to $450{ }^{\circ} \mathrm{C}$ for $1 \mathrm{~h}$ and $500{ }^{\circ} \mathrm{C}$ for $2 \mathrm{~h}$ at an average rate of $18{ }^{\circ} \mathrm{C} / \mathrm{min}$ under an air flow of $8 \mathrm{l} / \mathrm{min}$ in a muffle furnace equipped with an evacuation smokestack for combustion gases. The black powder obtained was then cooled to room temperature within $5 \mathrm{~min}$ in air. The black/grey powder was next washed by centrifugation three times with water and two times with ethanol in order to remove $\mathrm{LiCl}$. The clean and dry oxide nanopowder was finally annealed using an average ramp of $17^{\circ} \mathrm{C} /$ min up to $600{ }^{\circ} \mathrm{C}$ for $80 \mathrm{~min}$ to remove low temperature oxide phase impurities. These materials were used for the biohazard tests. $\mathrm{LiCoO}_{2}$ prepared with $\mathrm{LiOMe}$ and $\mathrm{LiO}^{t} \mathrm{Bu}$ was calcined further until $700{ }^{\circ} \mathrm{C}$ for $30 \mathrm{~min}$ to measure charge/discharge capacities at different current densities.

\section{Characterization}

\section{Single crystal $X$-ray structures}

Single crystals of compounds 1-5 and $\mathbf{9}$ were mounted on a loop and all geometric and intensity data were taken from these crystals. Data collection using Mo-K $\mathrm{K}_{\alpha 1}$ radiation $(\lambda=0.71073 \AA)$ was performed at $150 \mathrm{~K}$ on a STOE IPDS-II diffractometer equipped with an Oxford
Cryosystem open flow cryostat [49]. Absorption correction was partially integrated in the data reduction procedure [50]. The structure was solved by SIR 2004 and refined using full-matrix least-squares on $F^{2}$ with the SHELX-97 package [51, 52]. All heavy atoms could be refined anisotropically. Hydrogen atoms were introduced as fixed contributors when a residual electronic density was observed near their expected positions. Diffraction data sets for compounds 1-5 are unfortunately incomplete due to decomposition of the single crystals, resulting in poor data sets and $R$-values for the compounds. However, the isotropic attribution of heavy atoms is unambiguous.

Crystallographic data (excluding structure factors) for the structures in this paper have been deposited with the Cambridge Crystallographic Data Center, 12 Union Road, Cambridge CB21EZ, UK. Copies of the data can be obtained on quoting the depositing numbers CCDC1527018 (1), 1527022 (2), 1527023 (3), 1527020 (4), 1527019 (5), and 1527021 (9) (Fax: +44-1223-336-033; E-mail: deposit@ccdc.cam.ac.uk). Important crystal data for these compounds are given in the Additional file 1: Table S1.

\section{Other characterizations}

For powder XRD measurements, a Stoe IPDS II theta, equipped with monochromated Mo- $\mathrm{K}_{\alpha 1}$ radiation $(0.71073 \AA)$ was used in order to avoid X-ray fluorescence of the cobalt but also a Stoe STADIP, equipped with monochromated $\mathrm{Cu}-\mathrm{K}_{\alpha 1}$ radiation $(1.540598 \AA$ ) and Mythen detector. TGA was recorded on a Mettler Toledo TGA/SDTA851e in closed aluminium crucibles with a pin hole. Specific surface area was measured on a Micromeritics Gemini V series BET with a pre-treatment

Table 1 The reactants, synthetic conditions and the yields of the compounds 1, 8-12

\begin{tabular}{|c|c|c|c|}
\hline Compound & Formula & Reactants in synthesis & Yields (\%) \\
\hline 1 & {$\left[\mathrm{Co}(\mathrm{OPh})_{4} \mathrm{Li}_{2}(\mathrm{THF})_{4}\right]$} & $\mathrm{CoCl}_{2}(0.1 \mathrm{~g}, 0.77 \mathrm{mmol})+4 \mathrm{LiOPh} 1 \mathrm{M}$ in THF $(3.1 \mathrm{ml}, 3.1 \mathrm{mmol})$ & 82 \\
\hline 2 & {$\left[\mathrm{Co}(\mathrm{OPh})_{4} \mathrm{Li}_{2}(\mathrm{THF})_{4}\right] \cdot \mathrm{THF}$} & Idem as $\mathbf{1}$, but $-24^{\circ} \mathrm{C}$ under argon & 56 \\
\hline 3 & $\begin{array}{l}{\left[\mathrm{Co}(\mathrm{OPh})_{4} \mathrm{Li}_{2}(\mathrm{THF})_{2}\left(\mathrm{H}_{2} \mathrm{O}\right)\right.} \\
\left.\quad(\mathrm{THF})_{2}\right]_{2}\end{array}$ & Idem as $\mathbf{1}$, but $-24^{\circ} \mathrm{C}$ in air & $<10$ \\
\hline 4 & {$\left[\mathrm{Co}(\mathrm{OPh})_{4} \mathrm{Li}_{2}(\mathrm{TMEDA})_{2}\right]$} & Idem as $\mathbf{1}$, recrystallized from TMEDA & 69 \\
\hline 5 & {$\left[\mathrm{Co}(\mathrm{OPh})_{4} \mathrm{Li}_{2}(\text { dioxane })_{2}\right]_{\mathrm{n}}$} & Idem as $\mathbf{1}$, recrystallized from dioxane & 95 \\
\hline 6 & {$\left[\mathrm{Co}(\mathrm{OPh})_{4} \mathrm{Li}_{2}(\mathrm{DME})_{2}\right]$} & Idem as $\mathbf{1}$, recrystallized from DME & 47 \\
\hline 7 & {$\left[\mathrm{Co}(\mathrm{OPh})_{4} \mathrm{Li}_{2}(\mathrm{Py})_{4}\right]$} & Idem as $\mathbf{1}$, recrystallized from pyridine & 39 \\
\hline 8 & {$\left[\mathrm{Co}_{2}\left(\mathrm{O}^{t} \mathrm{Bu}\right)_{6} \mathrm{Li}_{4}(\mathrm{THF})_{2}\right]$} & $\mathrm{CoCl}_{2}(585 \mathrm{mg}, 4.5 \mathrm{mmol})+3 \mathrm{LiO}^{t} \mathrm{Bu} 1 \mathrm{M}$ in THF $13.5 \mathrm{ml}(13.5 \mathrm{mmol})$ & 87 \\
\hline 9 & {$\left[\mathrm{Co}_{2}\left(\mathrm{O}^{t} \mathrm{Bu}\right)_{2}(\mathrm{OPh})_{4} \mathrm{Li}_{2}(\mathrm{THF})_{4}\right]$} & $\begin{array}{l}\mathrm{CoCl}_{2}(500 \mathrm{mg}, 3.85 \mathrm{mmol})+\mathrm{LiO}^{t} \mathrm{Bu}(3.9 \mathrm{ml}, 3.9 \mathrm{mmol})+\mathrm{LiOPh} 1 \mathrm{M} \text { in THF }(7.7 \mathrm{ml} \text {, } \\
7.7 \mathrm{mmol})\end{array}$ & 85 \\
\hline 10 & {$\left[\mathrm{CO}_{2}\left(\mathrm{O}^{\prime} \mathrm{Pr}\right)_{6} \mathrm{Li}_{2}(\mathrm{THF})_{2}\right]$} & $\mathrm{CoCl}_{2}(500 \mathrm{mg}, 3.85 \mathrm{mmol})+3 \mathrm{LiO}^{\prime} \operatorname{Pr} 2 \mathrm{M}$ in THF $(5.8 \mathrm{ml}, 11.6 \mathrm{mmol})$ & 92 \\
\hline 11 & {$\left[\mathrm{CO}_{2}(\mathrm{OEt})_{12} \mathrm{Li}_{8}(\mathrm{THF})_{8-10}\right]$} & $\mathrm{CoCl}_{2}(500 \mathrm{mg}, 3.85 \mathrm{mmol})+6$ LiOEt $2 \mathrm{M}$ in THF $(11.6 \mathrm{ml}, 23.2 \mathrm{mmol})$ & 89 \\
\hline 12 & {$\left[\mathrm{CO}_{2}(\mathrm{OMe})_{6} \mathrm{Li}_{2}(\mathrm{THF})_{2}(\mathrm{MeOH})_{2}\right]$} & $\mathrm{CoCl}_{2}(500 \mathrm{mg}, 3.85 \mathrm{mmol})+3$ LiOMe $2 \mathrm{M}$ in THF $(5.3 \mathrm{ml}, 11.7 \mathrm{mmol})$ and $\mathrm{MeOH}$ & 90 \\
\hline
\end{tabular}


under vacuum at $150{ }^{\circ} \mathrm{C}$ for one night. SEM images were recorded on Phenom Desktop SEM and a FEI XL 30 Sirion FEG with Secondary Electron and EDS Energy Dispersive Spectrometer detectors. SEM samples were prepared by spraying them on a carbon tape glued on a SEM holder to reproduce the spraying in the exposure chamber. All images were obtained without sputter coating pretreatment. TEM images were recorded on a FEI/ Philips CM-100 Biotwin. Raman spectra were recorded with a confocal micro-Raman spectrometer, HORIBA LabRAM HR800, combined with an optical microscope Olympus BX41, using a red laser at $633 \mathrm{~nm}$ for excitation, attenuated with filters in order to avoid thermal degradation of the scotch tape used as sample holder. The $\mathrm{Li}^{+}$and $\mathrm{Co}^{2+/ 3+}$ ion concentrations were determined by inductively coupled plasma optical emission spectroscopy (ICP-OES) using a Perkin Elmer Optima 7000DV.

The muffle furnace used for combustion and tempering is equipped with a eurotherm thermal controller (Tony Güller Naber Industrieofenbau, Zurich, Switzerland).

\section{Metal ion release}

A metal ion release test was conducted to assess the amount of potential metal ion dissolution from the tested compounds. $100 \mathrm{mg}$ of each of the micro- and nanoparticles were immersed in $10 \mathrm{ml}$ of deionised water at $\mathrm{pH} 7$ and $\mathrm{pH} 4.5$ for $24 \mathrm{~h}$. The concentrations of the metal ions were then determined using ICP measurements (Additional file 1).

\section{Statistical and data analysis}

The microparticles of $\mathrm{LiCoO}_{2}$ are represented in black and the nanoparticles in grey bars. Data are the mean \pm the standard error of the mean (SEM) and are absolute values. Values were considered significantly different compared to the negative control with $\mathrm{p}<0.05$ using a one way Anova with a post hoc Tukey test ("nanoparticles, \#microparticles).

\section{Electrodes and electrochemical tests Preparation of the electrodes}

$0.5 \mathrm{~g}$ of the nanoscale- $\mathrm{LiCoO}_{2}$ and $10 \mathrm{wt} \%$ SFG graphite with respect to $\mathrm{LiCoO}_{2}$ were ball milled in a horizontal set-up (Retch MM 400) for 15 min at a frequency of $30 \mathrm{~Hz}$. The ball milling jar had a volume of $10 \mathrm{ml}$ and contained two stainless steel balls of $10 \mathrm{~mm}$ in diameter. The electrode paste was prepared in a glass tube, starting with polyvinylidene fluoride (PVDF) (10 wt\% with respect to $\mathrm{LiCoO}_{2}$ ) and $0.5 \mathrm{ml}$ of N-methyl-2-pyrrolidone (NMP), which were stirred by a mechanical stirrer for 30 min until PVDF was completely dissolved. $2 \mathrm{wt} \%$ of ABG graphite with respect to $\mathrm{LiCoO}_{2}$ was then added and the mixture was stirred for $15 \mathrm{~min}$. Then, the ball milled composite powder $(0.6 \mathrm{~g})$ of graphite and $\mathrm{LiCoO}_{2}$ were added to the $\mathrm{PVDF} /$ graphite/NMP mix and stirred for a half an hour. The so-obtained paste of PVDF/NMP/graphite/ $\mathrm{LiCoO}_{2}$ was spread onto an aluminum foil by the doctor-blade method and dried overnight at $120^{\circ} \mathrm{C}$. The overall weight ratio of the composite made of nano- $\mathrm{LiCoO}_{2}$ (active material), carbon and binder was around 78:12:10.

\section{Cell assembly}

All compounds used were dried to avoid HF formation in the electrolyte and were assembled in a glove box under argon (MBraun, Germany) having $<0.1 \mathrm{ppm}$ of water and oxygen. Typically, the $\mathrm{LiCoO}_{2}$ electrode was assembled in a coin cell using lithium metal as anode, a few drops of an ethyl carbonate (EC) and diethylene carbonate (DEC) mixture in a 1:1 volume ratio with $1 \mathrm{M} \mathrm{LiPF}_{6}$ and $2 \mathrm{wt} \%$ of vinylene carbonate as electrolyte with respect to solvents and $\mathrm{LiPF}_{6}$ as well as a Celgard separator.

\section{Battery tests}

A potentiostat, Princeton Applied Research 273A, and an Arbin battery test instrument (version 4.27) were used to examine the electrochemical properties of the carbon-nano- $\mathrm{LiCoO}_{2}$ composite electrodes. Charge and discharge capacities of coin cells were measured by an Arbin 2000 battery test instrument at different current densities of $\mathrm{C} / 20, \mathrm{C} / 10, \mathrm{C} / 5, \mathrm{C} / 2$ and $1 \mathrm{C}$. The voltage window was set between 2.6 and $4.4 \mathrm{~V}$ vs. $\mathrm{Li}^{+} / \mathrm{Li}$. The current densities between $C / 20$ and $1 C$ were based on the practical capacity of $140 \mathrm{mAh} / \mathrm{g}$.

Li-ion diffusion coefficients were evaluated by cyclic voltammetry at a sweep rate of $1,0.7,0.5,0.2$ and $0.1 \mathrm{mV} / \mathrm{s}$ between 3.5 and $4.4 \mathrm{~V}$ vs. $\mathrm{Li}^{+} / \mathrm{Li}$.

The discharge kinetic of $\mathrm{LiCoO}_{2}$ electrodes was investigated at various current densities between $20 \mathrm{C}$ and $\mathrm{C} / 20$. The $\mathrm{LiCoO}_{2}$ coin cells were re-charged until $4.4 \mathrm{~V} \mathrm{vs.} \mathrm{Li}^{+} /$ $\mathrm{Li}$ at $20 \mathrm{C}$ current density and then rested for $3 \mathrm{~min}$. The electrode was discharged at the same current density of $20 \mathrm{C}$ until $2.6 \mathrm{~V}$. This procedure was repeated at various lower current densities until C/20 (so-called deep discharge). By this procedure, the capacity vs. the discharge current can be determined directly. The sum of all capacities, obtained at different discharge currents is the maximum discharge capacity of the battery:

$$
\mathrm{C}_{\max }=I_{1} \cdot \mathrm{t}_{1}+I_{2} \cdot \mathrm{t}_{2}+\cdots+I_{\mathrm{n}} \cdot \mathrm{t}_{\mathrm{n}} .
$$

The equilibrium potentials of $\mathrm{LiCoO}_{2}$ electrodes were measured with the pulsed cycle method ( 3 min with applied current, followed by $3 \mathrm{~min}$ rest) in the range of potentials between 2.6 and $4.2 \mathrm{~V} \mathrm{vs.} \mathrm{Li}^{+} / \mathrm{Li}$. The equilibrium charge/discharge current was $\mathrm{C} / 10(15 \mathrm{~mA} / \mathrm{g})$. These procedures were described in detail by Spodaryk et al. [53]. 
The exchange current densities were calculated from the Tafel plot, i.e. dependence of current vs. overpotential. Currents $( \pm \mathrm{i})$, starting from the smallest to the highest, were alternatively applied and the potentials during the current flow were measured. From the overpotential (the difference between measured potential with the applied current and equilibrium potential, i.e. the potential which the electrode reaches during rest time), the exchange current densities were calculated. The detailed method is described by Chartouni et al. [54].

Electrochemical impedance spectroscopy data were obtained using a potentiostat/galvanostat PGSTAT302N with FRA module (Metrohm Autolab). Impedance spectra of the Li-ion batteries were measured in the range of working frequencies from $10 \mathrm{mHz}$ to $100 \mathrm{kHz}$. The range was built using a logarithmic distribution. The voltage modulation amplitude was $10 \mathrm{mV}$. The EIS spectra were analysed using fitting procedure in NOVA 1.4 software from Metrohm Autolab. The accuracy of the potentials measurements is $\pm 2 \mathrm{mV}$, of the current $\pm 2 \%$ and of the capacity $\pm 2 \%$.

The values of the elements from the equivalent circuit model (Additional file 1: Figure S10) were obtained by the following formulas:

$$
\mathrm{Z}_{\mathrm{Ri}}=\mathrm{R}_{\mathrm{i}}
$$

where $R_{i}$ is contact resistance or charge transfer resistance, Ohm, Constant phase element (CPE), which models the behavior of an imperfect capacitor or of a double layer, calculated by:

$$
Z_{Q}=\frac{1}{Y_{0}(j \omega)^{n}}
$$

where $Y_{0}$ is admittance of an ideal capacitance, siemens S; $n$ is an empirical constant, $0<n<1$ ( $n$ is frequency independent and in the case $n=1$ formula describes an ideal capacitor, $n=0$-resistor, $n=0.5$-Warburg impedance); $j$ is imaginary part of impedance; $\omega$ is angular frequency, $\mathrm{rad} / \mathrm{s}, \omega=2 \pi f ; f$ is frequency, $\mathrm{Hz}$.

The Warburg impedance is provided by:

$$
Z_{W}=\frac{1}{Y_{0} \sqrt{j \omega}}
$$

\section{Lung cell cultures}

All in vitro exposure experiments in this study were conducted with a 3D triple cell co-culture model of the human epithelial tissue barrier cultured at the ALI. This system has previously been described in detail $[39,55]$. Briefly, the model consists of a layer of human alveolar type II-like epithelial cells (A549, derived from the American Type Culture Collection) with human monocytederived macrophages (MDM) on the apical side (upper chamber) and monocyte-derived dendritic cells (MDDC) on the basolateral side (lower chamber). A549 epithelial cells were cultured at a density of $0.5 \times 10^{6}$ cells $/ \mathrm{ml}$ in cell culture medium RPMI 1640 (supplemented), on BD Falcon cell culture inserts (high pore density PET membranes, $4.2 \mathrm{~cm}^{2}$ growth area, $3.0 \mu \mathrm{m}$ pore size; Beckton Dickinson AG, Switzerland). The cell culture densities of MDM and MDDC were $5 \times 10^{4}$ and $25 \times 10^{4}$ cells/ insert, respectively [56].

Human blood monocytes were isolated from different, individual buffy coats received from the Swiss blood donation service (Bern, Switzerland) (i.e. different donor for each exposure), using $\mathrm{CD}_{14} 4^{+}$MicroBeads as described previously [57]. Due to this, variations in the background between different sets of cell cultures were expected to occur. Co-cultures were incubated for $24 \mathrm{~h}$ under suspension conditions in order to allow cellcell habituation. Subsequently, cell culture medium was extracted from the apical layer to allow formation of the ALI over a period of $24 \mathrm{~h}$ in the incubator prior to particle exposures.

\section{Air-liquid interface cell exposure system}

The dry powder insufflator (DP-4, Penn Century, USA) was used to pulverise the $\mathrm{LiCoO}_{2}$ particles. The particle exposure system consisted of a closed chamber $(15 \times 15 \times 35 \mathrm{~cm})$ coated with aluminium foil and equipped with a quartz crystal microbalance (QCM) for the in situ determination of the amount of material deposited. As the material settles onto the QCM, the frequency of the crystal changes $(\Delta \mathrm{F})$. The $\Delta \mathrm{F}$ value $(\mathrm{Hz})$ calculated from the recorded frequency values before and after deposition of material is converted to deposited mass per area $\left(\mu \mathrm{g} / \mathrm{cm}^{2}\right)$ as described in [58].

To avoid electrostatic blocking of the needle, aggregation, asymmetric deposition and low deposition yield, a stainless steel needle without bevel of $2 \mathrm{~mm} \varnothing$ and $7 \mathrm{~cm}$ of length was used as pulverization means with a gas expulsion flow of $\sim 120 \mathrm{ml} / \mathrm{s}$ of air in two pulse of $\sim 0.5 \mathrm{~s}$ for each exposure.

\section{Particles exposures}

As described for the aerosolisation of dry volcanic ash particles [59] the pulverisation of the dry powder of nanoparticles produces a radial distribution of the particles at the bottom of the chamber. In order to obtain a regular and reproducible distribution of particles on the cells, the 6-well culture plates were placed in such a way that the inserts holding the triple cell co-cultures and the QCM balance were disposed equidistant from the centre in a cross-like pattern as drawn in the scheme below (Fig. 1).

Two inserts/wells were used for each of the three different concentrations of nanoparticles and microparticles. Experiments were repeated 3-4 times for each of the two 


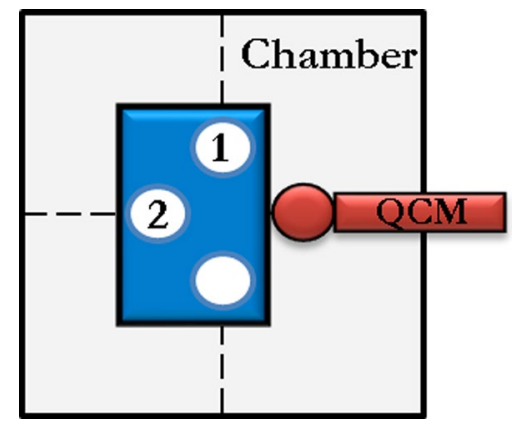

Fig. 1 Scheme of the exposure chamber bottom viewed from the top

particle sizes chosen (micronsize commercial particles and homemade nanoparticles). The pulverisation process took place over a period of about 1 month with each week a different blood donor source.

The samples (wells) were incubated overnight at $37{ }^{\circ} \mathrm{C}$ and $5 \% \mathrm{CO}_{2}$. The day after incubation, the supernatant was removed and replaced with $2 \mathrm{ml}$ of culture medium.

\section{Biological assays \\ Cytokine and chemokine quantification}

The pro-inflammatory response of the triple co-culture after exposure to $\mathrm{LiCoO}_{2}$ particles was quantified using the amount of the pro-inflammatory mediators which are tumor necrosis factor $\alpha$ (TNF- $\alpha$ ) and interleukin- 8 (IL-8) using commercial ELISA development kit and the related supplier protocol. The positive control for the pro-inflammatory proteins was treated with lipopolysaccharide $1 \mu \mathrm{g} / \mathrm{ml}$ (LPS) for $24 \mathrm{~h}$.

\section{Optical microscopy/LSM microscopy}

After the exposure, cells were fixed and labelled as previously described by Lehmann et al. [56]. In short, samples were stained with a $250 \mu \mathrm{l} \mathrm{mix} \mathrm{of} \mathrm{a} \mathrm{1:50} \mathrm{dilution} \mathrm{of} \mathrm{phal-}$ loidin-rhodamine for cell cytoskeleton and 1:100 dilution of 4',6-diamidino-2-phenylindole (DAPI) for the cell nuclei. Coverslips were then mounted onto microscope slides using Glycergel and imaged by LSM.

\section{Results}

\section{1-Solid states structures}

Compounds 1-7 were obtained by reacting $\mathrm{CoCl}_{2}$ with $\mathrm{LiOPh}$ in THF, followed by crystallization in THF under different conditions (temperature, presence of water or not, leading to compounds 1-3) or by eliminating the THF solvent and replacing it with other mono- or bisdentate ligands, like TMEDA, dioxane, DME, or pyridine (4-7). A general reaction scheme (Scheme 1) resumes the family of compounds obtained. We describe here the
$4 \mathrm{LiOPh}+\mathrm{CoCl}_{2} \stackrel{\text { solv }}{\longrightarrow}\left[\mathrm{Co}(\mu-\mathrm{OPh})_{4} \mathrm{Li}_{2}(\text { solv })_{\mathrm{x}}\right]+2 \mathrm{LiCl}$

solv $=$ THF, TMEDA, pyridine, DME or dioxane.

Scheme 1 General reaction scheme for obtaining compounds 1-7

single crystal structures of compounds $\mathbf{1 - 5}$, on which we base our structural discussion. For compounds $\mathbf{6}$ and 7 , the single crystal structures could not be determined as the single crystal quality was poor; yet, the chemical analyses confirm a chemical composition in analogy to the other five compounds.

Among the compounds, different structure types could be identified depending on the solvent present. For compounds 1-7, the core of the structure is essentially based on one central cobalt ion which is tetrahedrally coordinated by four phenolate entities, bridging pairwise to two lithium ions. The coordination spheres of the lithium cations are completed by coordinating solvent molecules, leading either to molecular entities or a coordination polymer in case of 5. Figure 2 shows as an example of such a core structure the one of compound $\mathbf{1}$. In compound $\mathbf{3}$, the terminal ligands of one of the two Li-ions have been formally replaced by two water molecules, which act as bridging ligands between two $\left[\mathrm{Li}_{2} \mathrm{Co}(\mathrm{OPh})_{4}\right]$ cores, leading thus to a dimer-type structure. Detailed structure descriptions for 1-5 with distances and angles are given in the Additional file 1: Text 2, while a resume is given in Table 6.

\section{Compounds 8-12}

For the compounds 8-12, the aim was to test ligands other than aryloxides, such as alkoxides, and to also mix aryloxides and alkoxides as ligands. The synthesis used is similar to the one for compound $\mathbf{1}$ (Scheme 2), but replacing the $\mathrm{LiOPh}$ with alkoxides or using a mix of both.

Since the precursor compounds 8, 10, 11 and 12 did not afford single crystals, other methods were used to approach their structure. In possible analogy to compound 8 , the sodium compound $\left[\mathrm{Na}_{2} \mathrm{Co}_{2}\left(\mathrm{O}^{t} \mathrm{Bu}\right)_{6}(\text { thf })_{2}\right]$ was described in the literature [60]. Since the sodium ions are coordinated by four ligands, similar to the preferred coordination of $\mathrm{Li}^{+}$, and since $\mathrm{Co}^{2+}$ tends to a tetrahedral coordination [61], we propose a similar structure for the lithium compound 8 (Fig. 3). The TGA and NMR measurements confirm that there are two THF molecules per three $\mathrm{O}^{t} \mathrm{Bu}$ ligands and the ICP measurement gives a ratio of one lithium for one cobalt ion.

The compounds 10-12 were also analyzed by TGA and NMR to determine the amount of ligand and solvent remaining in the solid state structure and the ratio between the ligand and the coordinating solvent 

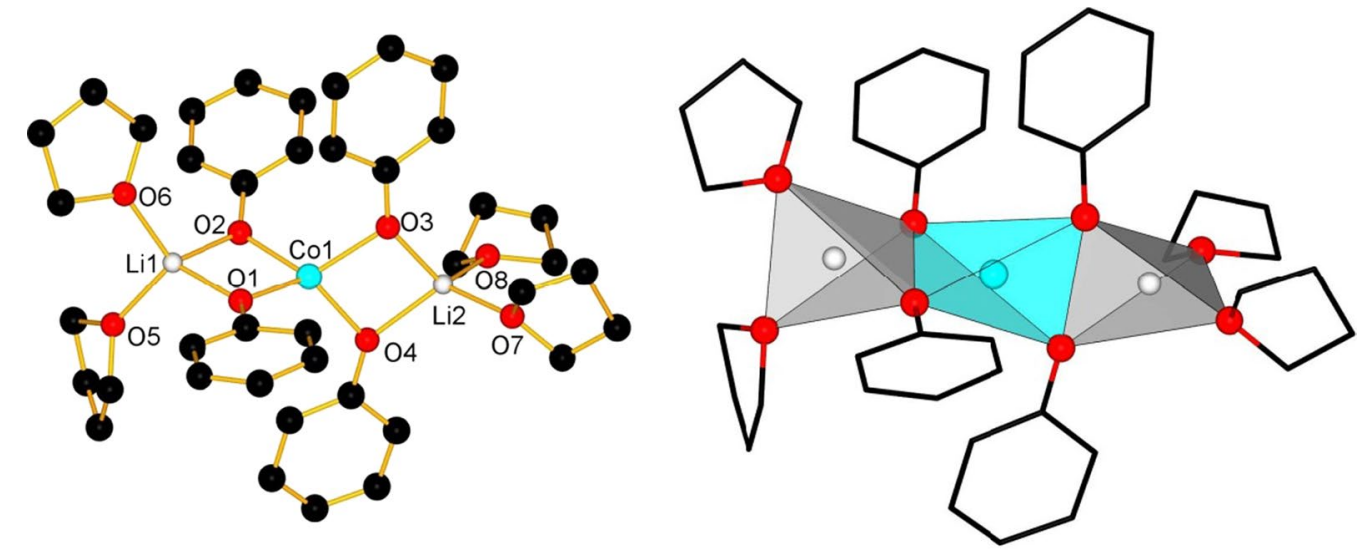

Fig. 2 Labelled view of the molecular structure of 1, H-atoms are omitted for clarity (left); coordination polyhedra in 1 (right)

$$
\begin{aligned}
& x \mathrm{CoCl}_{2}+y \mathrm{LiOR} \underset{30 \mathrm{~min}}{\stackrel{\mathrm{THF}, 66^{\circ} \mathrm{C}}{\longrightarrow}} \text { Complex }+2 x \mathrm{LiCl} \\
& \mathrm{R}=\mathrm{Ph},{ }^{\mathrm{t}} \mathrm{Bu},{ }^{\mathrm{i}} \mathrm{Pr}, \mathrm{Et}, \mathrm{Me} \\
& \mathrm{y}=3 \text { or more }
\end{aligned}
$$

Scheme 2 General reaction equation for the synthesis of compound 8-12

molecules. ICP measurements and argentometric titrations of chloride (Additional file 1: Table S3) were also performed to evaluate the ratio of lithium per cobalt ions and the amount of $\mathrm{LiCl}$ remaining in the material. The results are resumed in Table 2 .
From the synthesis, we observed that three equivalents of ligand are required to form carbonate-free $\mathrm{LiCoO}_{2}$ from this precursor 10. The low amount of impurity of mainly $\mathrm{Li}_{2} \mathrm{CO}_{3}$ after combustion indicates that there is no excess of unreacted lithium precursor. We also found one $\mathrm{Li}^{+}$for one $\mathrm{Co}^{2+}$ ion in the complex as well as two THF molecules. From this data we propose that the $\mathrm{O}^{i} \mathrm{Pr}$-compound possesses a structure similar to the $\mathrm{O}^{t} \mathrm{Bu}$-precursor 8 (Fig. 4). Using the same method for the compound $\mathbf{1 2}$ and based on the findings shown in Table 2, we can propose a similar structure as for $\mathbf{8}$ (Fig. 4). The extra methanol molecules are difficult to assess since both methanol and THF have almost the same boiling point. Finally, NMR measurements are not

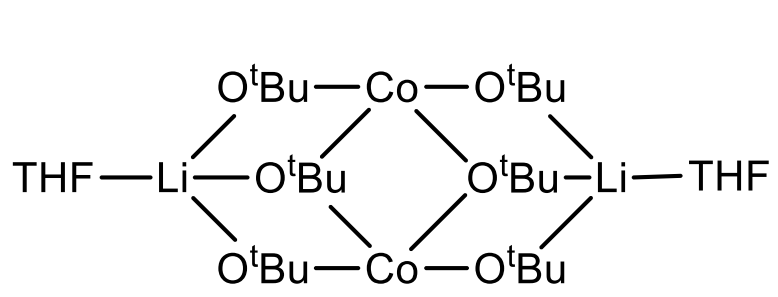

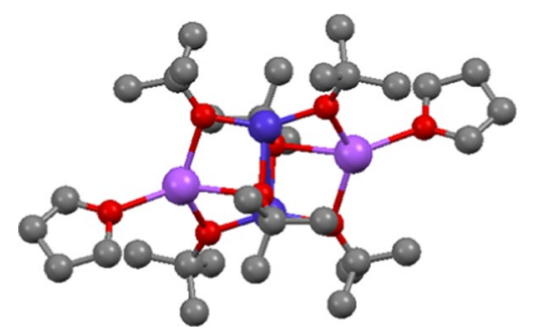

Fig. 3 Proposed structure for 8 (left) based on the $\left[\mathrm{Na}_{2} \mathrm{CO}_{2}\left(\mathrm{O}^{t} \mathrm{Bu}\right)_{6}(\text { thf })_{2}\right]$ compound (right, dark blue Co, violet $\mathrm{Na}$, red $\mathrm{O}$, grey $\mathrm{C}_{;}$H-atoms omitted

\begin{tabular}{|c|c|c|c|c|}
\hline Compound no-reagent & Ligand eq. vs. Co eq. & Solvent molecules per complex & Free lithium (eq.) & $\mathrm{LiCl}$ (eq.) \\
\hline $8-\mathrm{LiO}^{t} \mathrm{Bu}$ & 3 & 4 (residual THF) & 1 Li per Co & 2 Li per Co \\
\hline 9— $\mathrm{LiO}^{t} \mathrm{Bu}+\mathrm{LiOPh}$ & $1+2(3)$ & 4 & 1 Li per Co & 2 Li per Co \\
\hline 10- $\mathrm{LiO}^{\prime} \mathrm{Pr}$ & 3 & $2 \mathrm{THF}$ & 1 Li per Co & 2 Li per Co \\
\hline 11-LiOEt & 6 & 4-5 THF & 4 Li per Co & 2 Li per Co \\
\hline 12-LiOMe & 3 & $2 \mathrm{THF} / 2 \mathrm{MeOH}$ & 1 Li per Co & 2 Li per Co \\
\hline
\end{tabular}
described in [60]

Table 2 Combined results from TGA, NMR, ICP and argentometric titration for compounds 8-12 
helpful since the broadening of the signals (due to the paramagnetic influence of the cobalt ion) hides most of the possible peak shifts.

The compound $\mathbf{1 1}$ is the only one which does not follow this rule of three ligands per $\mathrm{Co}^{2+}$ and requires six ligands per $\mathrm{Co}^{2+}$ to form the desired oxide without impurities of $\mathrm{Co}_{3} \mathrm{O}_{4}$. An open double heterocubane structure is proposed, as it combines the minimum amount of ligands, the amount of free lithium for coordination, the amount of THF and the preferred coordination of lithium ions (4) and cobalt ions $(4,6)$ as determined by TGA, NMR, ICP and argentometric titration (Fig. 4).

Compound 9 is an interesting mixed ligand compound as it forms molecules of $\left[(\text { thf })_{2} \mathrm{Li}(\mu-\mathrm{OPh})_{2} \mathrm{Co}\left(\mu-\mathrm{O}^{t} \mathrm{Bu}\right)\right]_{2}$ where the two $\mathrm{O}^{t} \mathrm{Bu}$ groups act as bridging ligands between two $\mathrm{Co}^{2+}$ ions. The OPh ligands bridge pairwise between the cobalt and lithium ions, while two THF molecules complete the coordination of the lithium ions (Fig. 5). A detailed description with distances and angles is given in the Additional file 1: Table S1 and Text 2. The bond valence sums are $>2$ for both cobalt ions and $>1$ for both lithium ions, indicating sufficient good coordination of the metal ions by their ligands, as it is also the case for compounds 1-5 (Table 6).

\section{Thermal decomposition to $\mathrm{LiCoO}_{2}$}

Among all compounds, $\mathbf{2}$ and $\mathbf{3}$ are difficult to handle as they lose their solvent molecules very quickly. The compounds 4-7 are not well suited for the formation of oxide at low temperature because of their relatively high boiling point, high carbon content and molecular weight. The following investigations for the formation of $\mathrm{LiCoO}_{2}$
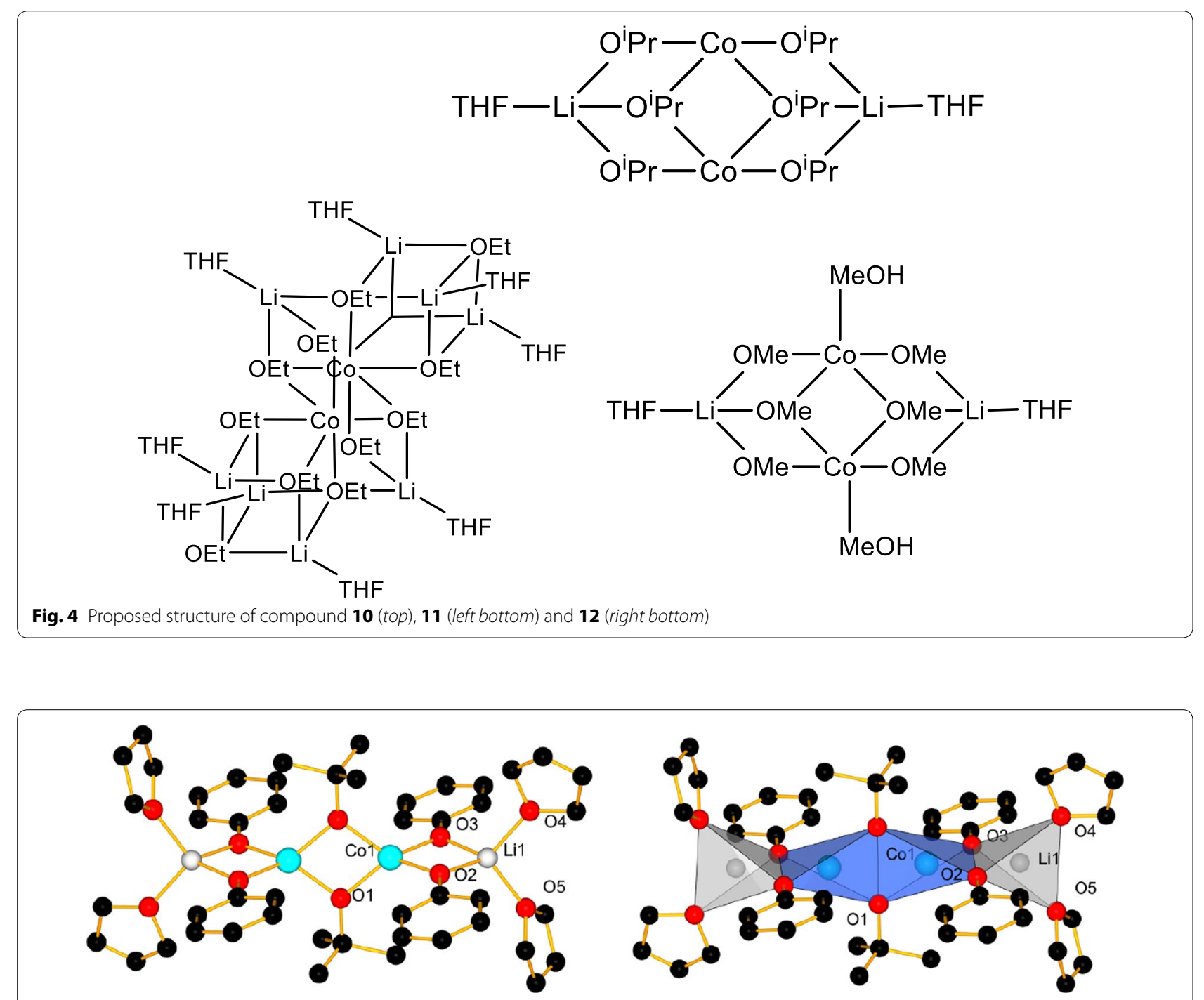

Fig. 5 Molecular view of compound $\mathbf{9}$ measured by XRD. H-atoms are omitted for clarity 
were thus limited to compounds containing THF and the less carbon containing compounds, hence $\mathbf{1}$ and $\mathbf{8}$ to $\mathbf{1 2}$.

In order to use these compounds as precursors for the manufacturing of $\mathrm{LiCoO}_{2}$, TGA measurements under oxygen atmosphere with open crucible were performed on the chosen compounds (Fig. 6). The general decomposition process of these complexes begins with the loss of the coordinated and residual non-coordinated solvent molecules before $120^{\circ} \mathrm{C}$ (THF B.P. $66^{\circ} \mathrm{C}$, MeOH $65^{\circ} \mathrm{C}$ ). At higher temperature, between ca. 100 and $400{ }^{\circ} \mathrm{C}$ depending on the precursor, the combustion process occurs: it consists of an oxidation of the $\mathrm{Co}^{2+}$ to $\mathrm{Co}^{3+}$ and of the ligand carbon backbone combustion. Above the temperature of $450{ }^{\circ} \mathrm{C}$, the masses remain quasi constant (Fig. 6). The completed combustion temperature and the detail thermal measurement information are described in Additional file 1: Tables S4 and S5.

Based on the minimum temperature of decomposition of the complexes determined by TGA, combustion tests were performed at different temperatures. Heating to the minimal temperature of decomposition of the precursors of $300{ }^{\circ} \mathrm{C}$ for $1 \mathrm{~h}$ lead to the formation of the HT-LCO phase with some byproducts $\left(\mathrm{Li}_{2} \mathrm{CO}_{3}\right)$ (Fig. 7a). Since $\mathrm{Li}_{2} \mathrm{CO}_{3}$ is highly soluble in water, it was removed after rinsing. We believe that the formation of HT-LCO at such a low temperature is possible due to the preorganization of metal ions within the heterobimetallic single source precursors. We decided nevertheless to increase the decomposition temperature by $50-100{ }^{\circ} \mathrm{C}$ compared to the decomposition temperature of the compounds in order to reduce the amount of byproducts, and for comparison purposes, the temperature was set to $450{ }^{\circ} \mathrm{C}$ for $1 \mathrm{~h}$ for all compounds.

After indexation of the powder diffractograms obtained after combustion at $450{ }^{\circ} \mathrm{C}$, all of the tested precursors $(1,8-12)$ afforded $\mathrm{LiCoO}_{2}$ with low amounts of impurities that could not be detected by powder X-ray analysis after washing with water, hence less than $5 \%$ (Fig. 7). Heating to the minimal temperature of decomposition of the precursors of $300{ }^{\circ} \mathrm{C}$ for $1 \mathrm{~h}$ leads to the
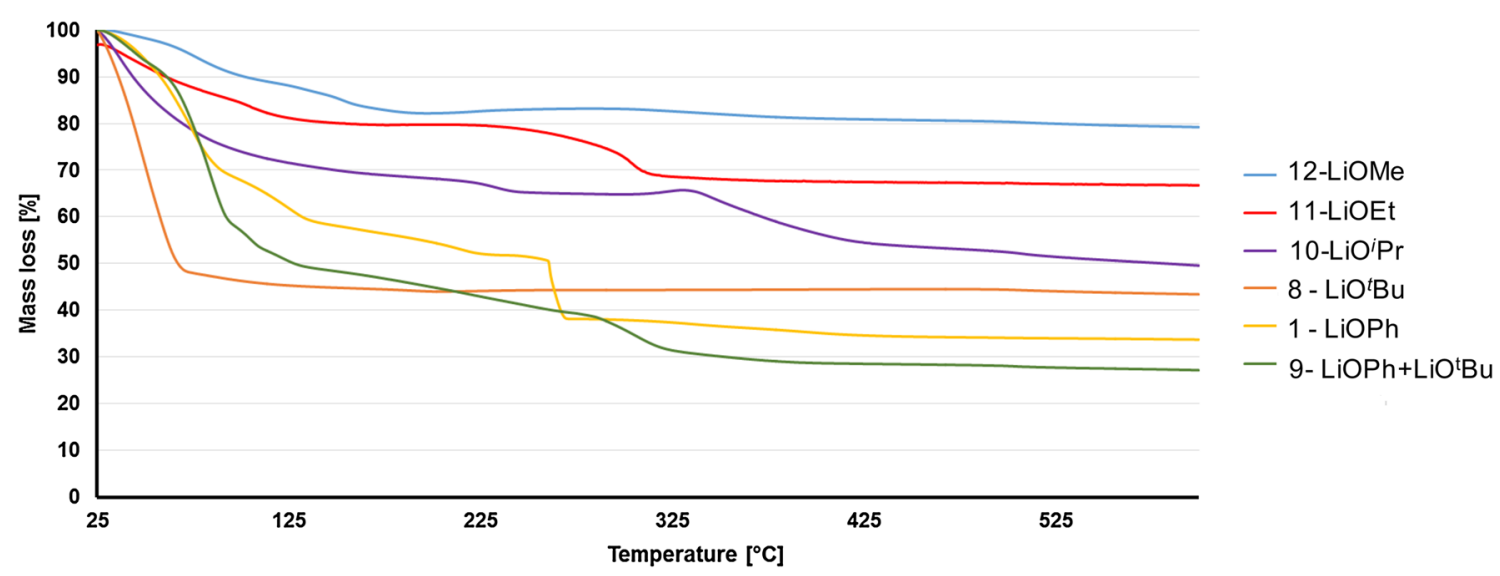

Fig. 6 TGA measurements of complexes $\mathbf{1}, \mathbf{8}, \mathbf{9}, \mathbf{1 0}, \mathbf{1 1}, 12$

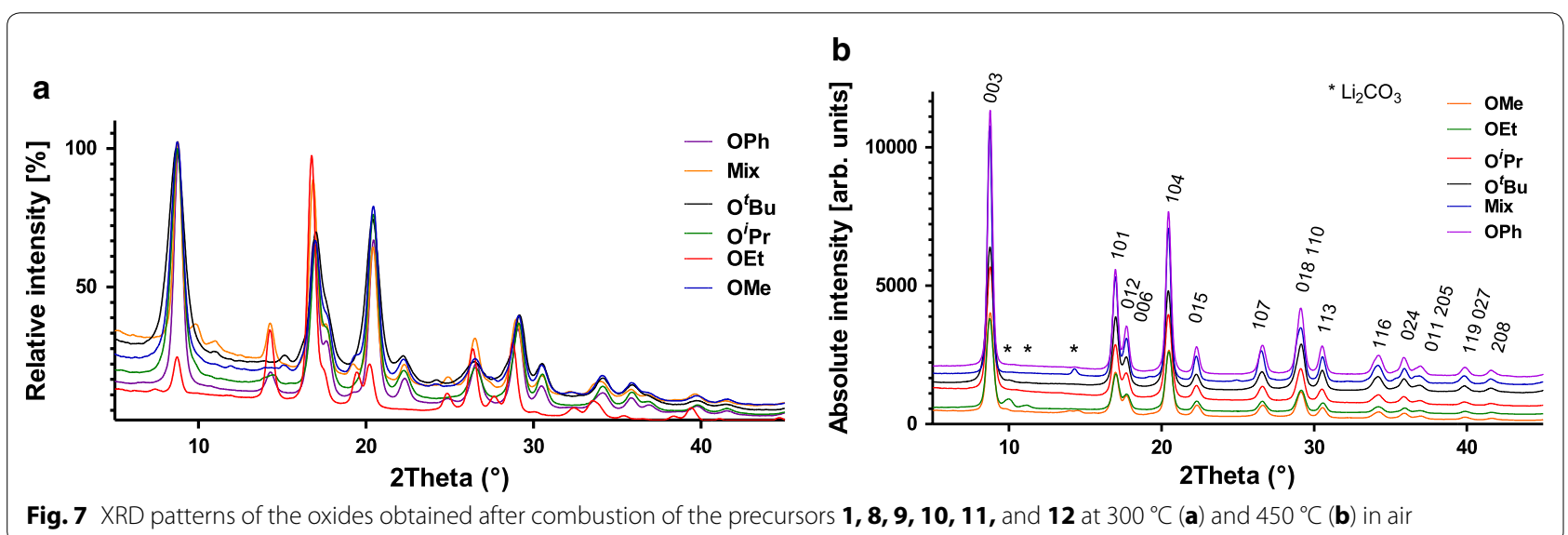


formation of the HT-LCO phase with some byproducts (among which $\mathrm{Li}_{2} \mathrm{CO}_{3}$ ). A Rietveld refinement of the different diffractograms, taken on a Mo source, was performed to determine the exact phase of the oxide. The lattice cell parameters from the different precursors correspond to a slightly distorted HT-LCO, with the space group $R-3 \mathrm{~m}$. This small distortion of the unit cells arises from the fact that this material is composed of nanocrystallites which possess a more strain than standard micrometric crystallites. The $c / a$ ratio gives also an indication on the general cation ordering of the oxide phase. If the $c / a$ ratio is 4.899 or lower, it means that it is a cation-disordered rock salt structure, also called the LT-LCO with a spinel structure $(F \mathrm{~d} 3 \mathrm{~m})$. Since this ratio $c / a$ is higher than this value in all cases, it indicates that the high temperature phase has been obtained for all precursors (Table 3).

Another method to identify LT and $\mathrm{HT}$ phases of $\mathrm{LiCoO}_{2}$ is to verify the peaks at 2 theta $=65-67^{\circ}\left(\lambda=\mathrm{Cu}-\mathrm{K}_{\alpha 1}\right)$. The HT-LCO has two split peaks of the (108) and (110) planes while the LT-LCO has one single peak of the (440) plane at $65^{\circ}[13,62]$. As shown in Fig. 8 below, all the materials prepared with $\mathrm{O}^{t} \mathrm{Bu}, \mathrm{O}^{i} \mathrm{Pr}$, OMe and OPh show two split peaks corresponding to the HT-LCO phase.

After thermal treatment at $450{ }^{\circ} \mathrm{C}$, the morphologies of the materials prepared with different precursors were analyzed using SEM (Fig. 9). All the materials show polyhedral shapes but the materials obtained from $\mathrm{LiO}^{i} \mathrm{Pr}$ and $\mathrm{LiOPh}$ precursors formed rhombohedral and triangle shapes.

Since the detection limit in powder X-ray diffraction is $3-5 \%$, Raman spectroscopy was used to complete the analysis. The HT-LCO possesses only two Raman active modes: $\mathrm{A}_{1 \mathrm{~g}}\left(\mathrm{Co}-\mathrm{O}\right.$ stretching) $\mathrm{v}_{1}$ at $595 \mathrm{~cm}^{-1}$ and $\mathrm{E}_{\mathrm{g}}(\mathrm{O}-$ Co-O bending) $v_{2}$ at $485 \mathrm{~cm}^{-1}$, while LT-LCO has four Raman active modes $\left(\mathrm{A}_{1 \mathrm{~g}}, \mathrm{E}_{\mathrm{g}}, 2 \mathrm{~F}_{2 \mathrm{~g}}\right)$ which are respectively at $v=590,484,605$ and $449 \mathrm{~cm}^{-1}$ and are due to the mixing of cations in the structure [63].

The Raman spectrum of our non-annealed nano-LCO obtained from compound $\mathbf{8}$ shows a contamination of the

Table 3 Cell parameters of the $\mathrm{LiCoO}_{2}$ formed using different precursors and HT-LiCoO 2 Ref. [61]

\begin{tabular}{|c|c|c|c|c|}
\hline Compound & $a$ & c & $c / a$ & Volume $\left(\AA^{3}\right)$ \\
\hline HT-LiCoO 2 [61] & $2.8156(6)$ & $14.0542(6)$ & 4.99 & $96.49(4)$ \\
\hline $1(\mathrm{LiOPh})$ & $2.8193(2)$ & 13.930(3) & 4.94 & $95.88(3)$ \\
\hline $8\left(\mathrm{LiO}^{t} \mathrm{Bu}\right)$ & $2.8179(3)$ & 13.949(3) & 4.95 & 95.93(4) \\
\hline $9\left(\mathrm{LiOPh}+\mathrm{LiO}^{t} \mathrm{Bu}\right)$ & $2.8139(3)$ & 13.970(4) & 4.96 & $95.79(4)$ \\
\hline $10\left(\mathrm{LiO}^{\prime} \mathrm{Pr}\right)$ & 2.8199(1) & $13.936(2)$ & 4.94 & $95.97(2)$ \\
\hline 11 (LiOEt) & $2.8144(2)$ & $13.942(2)$ & 4.95 & $95.64(2)$ \\
\hline 12 (LiOMe) & $2.8199(2)$ & $13.956(3)$ & 4.95 & $96.11(3)$ \\
\hline
\end{tabular}

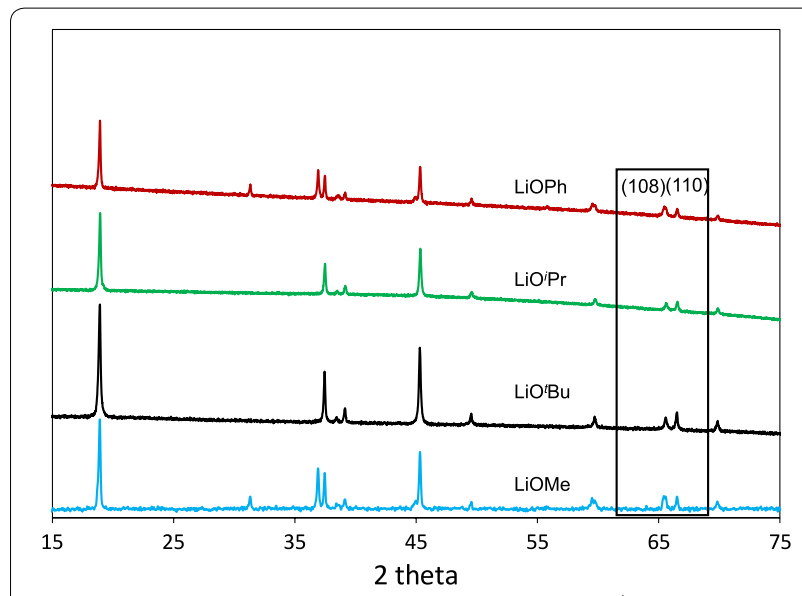

Fig. 8 XRD of $\mathrm{LiCOO}_{2}$ prepared with $\mathbf{8}-\mathrm{LiO}^{t} \mathrm{Bu}, \mathbf{1 0}-\mathrm{LiO}^{\prime} \mathrm{Pr}$, 12-LiOMe and $\mathbf{1}$-LiOPh precursors

HT-LCO with the LT phase which can be easily removed by annealing at $600{ }^{\circ} \mathrm{C}$ for $1 \mathrm{~h}$. No significant improvement can be observed for a $700{ }^{\circ} \mathrm{C}$ annealing (Fig. 10). In order to avoid particle growth due to coalescence and ripening, the duration and temperature of annealing have to be minimized, hence we used the $600{ }^{\circ} \mathrm{C}$ annealed nanoparticles for the biological assays described later.

ICP measurements on the nano-LCO obtained from 8 and on commercial micron-sized LCO were carried out and the ratio between $\mathrm{Li}^{+}$and $\mathrm{Co}^{3+}$ ions was calculated: we found $0.96 \pm 0.02 \mathrm{Li}^{+}$ions per $\mathrm{Co}^{3+}$ ion for the nanoLCO (Additional file 1: Table S4). Thus the stoichiometry is a little bit lower than the optimal 1:1 stoichiometry ratio. This can be explained at least partly by the washing steps during which part of the $\mathrm{Li}^{+}$can be washed away, the mechanical stress induced by ultrasounds and the shear stress of the centrifuge and the annealing in which the $\mathrm{Li}^{+}$and $\mathrm{Co}^{3+}$ ions can diffuse out of the oxide into the crucible. The ICP measurements of the micro- $\mathrm{LCO}$ give a $\mathrm{Li}^{+}$content of $1.01 \pm 0.02$ which is the optimal ratio for the HT-LCO.

\section{Morphologies and determination of the particle and crystallite sizes}

The crystallite and particle sizes were assessed via the Scherrer equation (X-ray) and the BET equation (gas adsorption), respectively. The details are described in the Additional file 1: Equation S1 - S5.

Table 4 gives the summary of specific surface area, different sizes of particles and crystallites obtained under identical combustion conditions (temperature, time, speed of heating/cooling and atmosphere composition) depending on the starting complexes. 

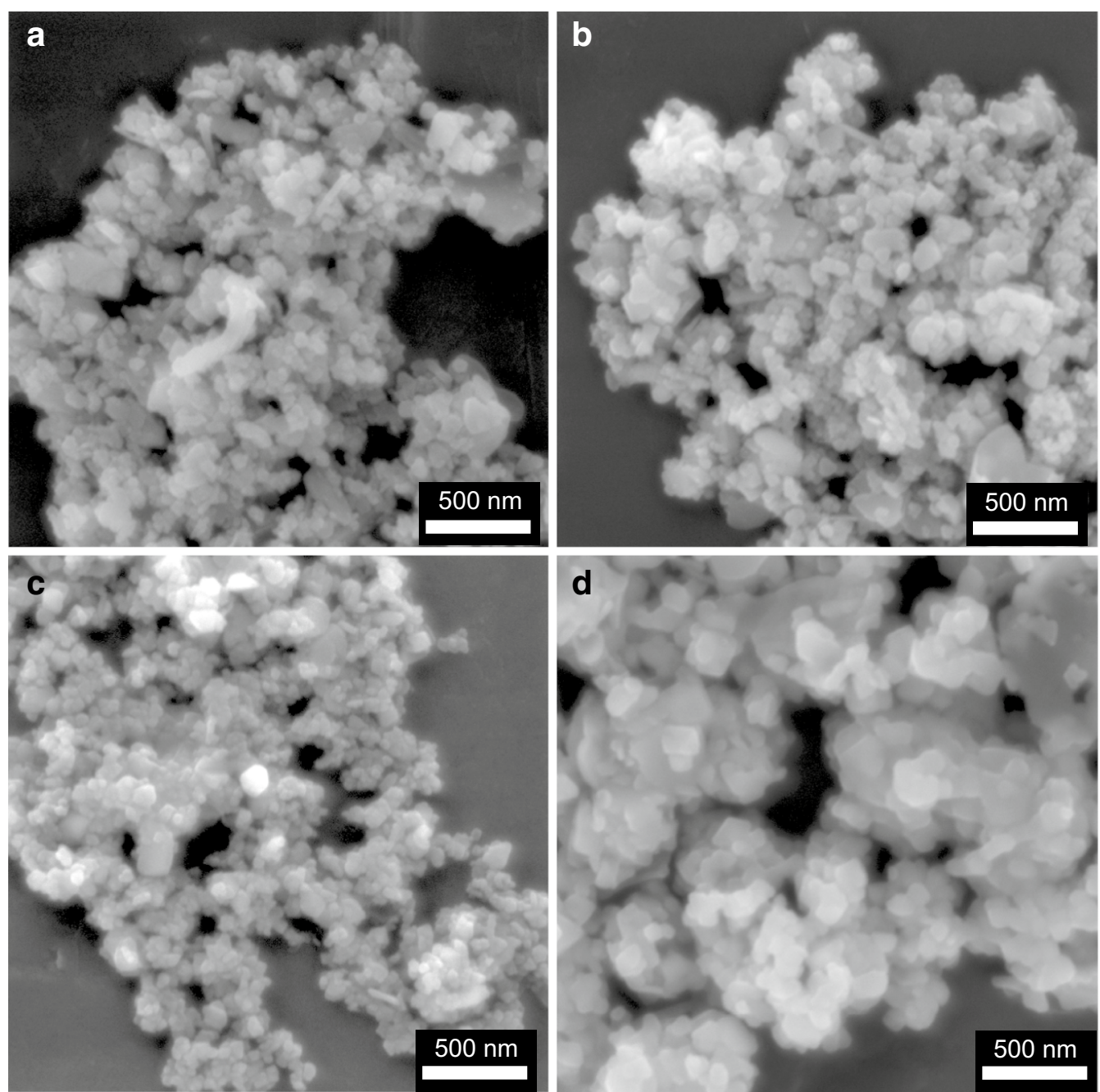

Fig. $9 \mathrm{SEM}$ images of $\mathrm{LiCoO}_{2}$ prepared with 8-LiO'B Bu (a), 10-LiO'Pr (b), 12-LiOMe (c), and 1-LiOPh (d) at $450{ }^{\circ} \mathrm{C}$ for $1 \mathrm{~h}$

The morphologies of the particles were investigated by SEM images (Fig. 11). The shapes of the particles obtained from the different precursors are similar and submicron. It is also noted that the material always tends to form large aggregates due to its high surface area.

\section{Electrochemistry and Li-ion diffusion}

Finally, in order to learn if the size of particles has a direct influence on the Li-ion diffusion, cyclic voltammetry of $\mathrm{LiCoO}_{2}$ electrodes was performed on two different particles sizes: 40 and $15 \mathrm{~nm}$ coming from the precursors 8 and 12, respectively after a prolonged ball milling of $1 \mathrm{~h}$ instead of $15 \mathrm{~min}$.

Figure 12a shows the cyclic voltammograms of $\mathrm{LiCoO}_{2}$ electrode prepared with $\mathrm{LiO}^{t} \mathrm{Bu}$ precursor at different scan rates between 0.1 and $1 \mathrm{mV} / \mathrm{s}$.
When $\mathrm{Li}^{+}$is extracted from $\mathrm{LiCoO}_{2}, \mathrm{Co}^{3+}$ in $\mathrm{LiCoO}_{2}$ is oxidized and electron is released $\left(\mathrm{LiCo}^{3+} \mathrm{O}_{2} \rightarrow \mathrm{Li}_{1-}\right.$ $\left.{ }_{\mathrm{x}} \mathrm{Co}^{4+/ 3+} \mathrm{O}_{2}+\mathrm{xe}^{-}+\mathrm{xLi}^{+}\right)$. On the other hand, oxidized $\mathrm{Li}_{1-x} \mathrm{CoO}_{2}$ is reduced and electron is uptaken when $\mathrm{Li}^{+}$is re-inserted into $\mathrm{Li}_{1-x} \mathrm{CoO}_{2}\left(\mathrm{Li}_{1-x} \mathrm{Co}^{4+/ 3+}\right.$ $\left.\mathrm{O}_{2}+\mathrm{xe}^{-}+\mathrm{xLi}^{+} \rightarrow \mathrm{LiCo}^{3+} \mathrm{O}_{2}\right)$. Therefore, the current increased where the redox reactions of $\mathrm{Co}^{3+} / \mathrm{Co}^{4+}$ occurred above $3.9 \mathrm{~V}$ for anodic peaks and between 3.6 and $3.9 \mathrm{~V} \mathrm{vs} . \mathrm{Li}^{+} / \mathrm{Li}$ for cathodic peaks. The $\mathrm{CVs}$ and the maximum current peaks of the compound $\mathbf{1 2}$ are shown in Additional file 1: Figure S9.

The Li-ion diffusion coefficient can be determined from these cyclic voltrammograms by using the Randle-Sevcik equation. The Randles-Sevcik equation [63]:

$$
\mathrm{Ip}=\left(2.69 \times 10^{5}\right) \mathrm{n}^{3 / 2} \mathrm{~A} \mathrm{D}_{\mathrm{Li}}^{1 / 2} \mathrm{Cv}^{1 / 2}
$$




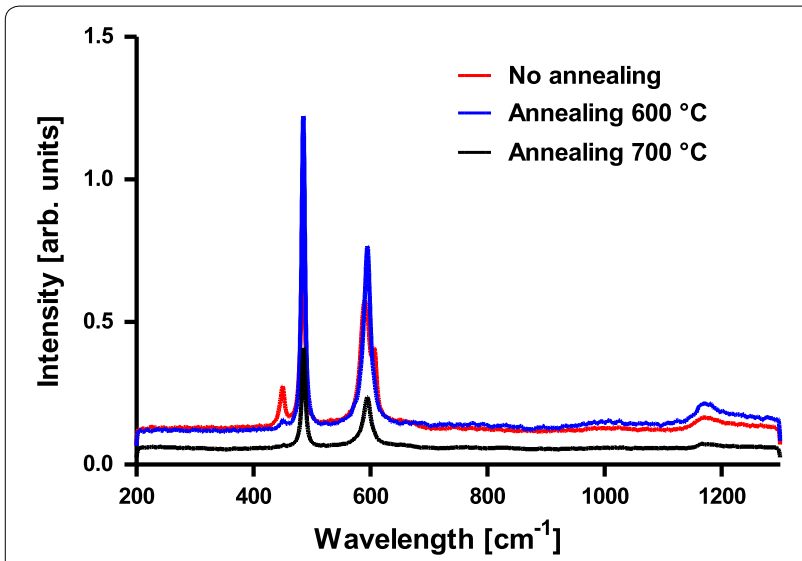

Fig. 10 Raman spectra of the annealed nano-LiCoO 2 obtained from compound $\mathbf{8}$ at different temperatures and annealing steps $\left(0 \mathrm{x}=500^{\circ} \mathrm{C}\right.$ for $2 \mathrm{~h}, 1 \mathrm{x}=$ first annealing at $600^{\circ} \mathrm{C}$ for $1 \mathrm{~h}$ and $2 \mathrm{x}=$ second annealing at $700^{\circ} \mathrm{C}$ for $\left.30 \mathrm{~min}\right)$

with Ip the peak current; $\mathrm{n}$ the number of transfer electrons; A the surface area of the electrode; $\mathrm{C}$ the concentration of reactants; and $\mathrm{v}$ the scan rate.

The plot of the square root of the scan rate vs. the anodic or cathodic peaks gives the slopes which represent the square root of the $\mathrm{Li}^{+}$ion diffusion coefficient value, $\mathrm{D}_{\mathrm{Li}+}$ (Fig. 12b).

The $\mathrm{Li}^{+}$ion diffusion coefficients $\left(\mathrm{D}_{\mathrm{Li}+}\right)$ of our nanoparticles were $2.3 \times 10^{-5}$ and $4.5 \times 10^{-6} \mathrm{~cm}^{2} \mathrm{~s}^{-1}$ for $8-\mathrm{LiO}^{t} \mathrm{Bu}$ and 12-LiOMe, respectively while the one of commercial HT-LCO was $2 \times 10^{-7} \mathrm{~cm}^{2} \mathrm{~s}^{-1}$ (Table 5). The values obtained from nanoparticles are 20-100 higher than the standard value for HT-LCO [64]. Thus the kinetics with $\mathrm{Li}^{+}$ions are much faster in nanoscale LCO than in micron-LCO. When we compare the values of diffusion coefficients of 15 and $40 \mathrm{~nm}$ of nano-LCO, the larger particle size of $40 \mathrm{~nm}$ has even higher diffusion coefficient. It will be explained in the discussion part later.

\section{Electrochemical properties}

After $\mathrm{D}_{\mathrm{Li}+}$ was determined, the battery properties of our nanoscale LCO materials were investigated. The charge/ discharge current is expressed as a C-rate to evaluate battery capacities at various current values. A C-rate is a measure of the rate at which a battery is discharged relative to its maximum capacity. The current density and $\mathrm{C}$-rate are determined by the nominal specific capacity of $150 \mathrm{mAh} / \mathrm{g}$. For example, the current densities are 150 and $7.5 \mathrm{~mA} / \mathrm{g}$ at $1 \mathrm{C}$ (a battery is charged in $1 \mathrm{~h}$ ) and $\mathrm{C} / 20$ (a battery is charged in $20 \mathrm{~h}$ ), respectively. Figure 13 shows the discharge capacities of $\mathrm{LiCoO}_{2}$ electrodes prepared by the precursors $1-\mathrm{LiOPh}, 8-\mathrm{LiO}^{t} \mathrm{Bu}, 10-\mathrm{LiO}^{i} \mathrm{Pr}$ and 12-LiOMe. Depending on the precursor used in the synthesis, the specific capacity varies. 10- $\mathrm{LiO}^{i} \mathrm{Pr}$ and $\mathbf{1 -}$ $\mathrm{LiOPh}$ derived $\mathrm{LiCoO}_{2}$ electrodes obtained superior capacities to the ones obtained with 8 - $\mathrm{LiO}^{t} \mathrm{Bu}$ precursors. The mean specific capacity of $\mathrm{LiCoO}_{2}$ derived from 1-LiOPh was $210 \mathrm{mAh} / \mathrm{g}$ at $\mathrm{C} / 20$, which is $77 \%$ of the theoretical capacity of $272 \mathrm{mAh} / \mathrm{g}$, while $\mathrm{LiCoO}_{2}$ from the $\mathrm{LiO}^{t} \mathrm{Bu}$ precursor had $124 \mathrm{mAh} / \mathrm{g}$ ( $46 \%$ of the theoretical value) at the same rate.

After cycling of charge/discharge at different current densities, we disassembled the batteries for all four samples and rinsed the $\mathrm{LiCoO}_{2}$ electrodes to verify their structures. XRD in Fig. 14 shows that all the cycled $\mathrm{LiCoO}_{2}$ electrodes have two peaks at (108) and (110) corresponding to the HT-LCO phase, hence the structure is unchanged after cycling.

Table 4 The specific surface area, mean particle size and crystallite size of $\mathrm{LiCoO}_{2}$ prepared with different precursors

\begin{tabular}{|c|c|c|c|c|c|c|c|c|c|c|c|c|}
\hline \multicolumn{13}{|l|}{$\mathrm{SSA}\left(\mathrm{m}^{2} / \mathrm{g}\right)$} \\
\hline Annealed & \multicolumn{2}{|l|}{ 1-LiOPh } & \multicolumn{2}{|l|}{ 8-LiO ${ }^{t} \mathrm{Bu}$} & \multicolumn{2}{|c|}{ 9-(LiOPh + LiO'Bu) } & \multicolumn{2}{|c|}{ 10-LiO'Pr } & \multicolumn{2}{|l|}{ 12-LiOMe } & \multicolumn{2}{|l|}{ 11-LiOEt } \\
\hline $500^{\circ} \mathrm{C}$ & $9.46(025)$ & & $16.50(0.2)$ & & $9.62(0.2)$ & & $11.50(0.3$ & & $19.70(0.12)$ & & not measured & \\
\hline $600^{\circ} \mathrm{C}$ & $2.59(0.015)$ & & $12.50(0.14)$ & & $0.95(0.03)$ & & $3.65(0.05$ & & $8.00(0.07)$ & & $0.95(0.01)$ & \\
\hline $700^{\circ} \mathrm{C}$ & $0.50(0.02)$ & & $6.10(0.17)$ & & $0.78(0.02)$ & & $3.04(0.05$ & & $5.50(0.05)$ & & $0.34(0.02)$ & \\
\hline \multicolumn{13}{|c|}{ Particle size $(P)^{*}$ and crystal size $(C)^{* *}(n m)$} \\
\hline & $P(1)$ & $C(1)$ & $\mathrm{P}(\mathbf{8})$ & $C(8)$ & $\mathrm{P}(9)$ & $C(9)$ & $\mathrm{P}(\mathbf{1 0})$ & $C(10)$ & $P(12)$ & $C(12)$ & $P(11)$ & $C(11)$ \\
\hline $500^{\circ} \mathrm{C}$ & $126(2)$ & $50(2)$ & $72(1)$ & $60(2)$ & $124(2)$ & $75(2)$ & $103(2)$ & $40(1)$ & $60(1)$ & $50(4)$ & Not measured & Not measured \\
\hline $600^{\circ} \mathrm{C}$ & $459(2)$ & $45(2)$ & $95(1), 40^{* * *}$ & $45(3)$ & $1251(26)$ & $150(3)$ & $326(3)$ & $75(1)$ & $149(1), 15^{* * *}$ & $45(1)$ & $1251(9)$ & $110(3)$ \\
\hline $700^{\circ} \mathrm{C}$ & $2376(60)$ & $90(2)$ & $195(4)$ & $55(2)$ & $1529(26)$ & $185(1)$ & $391(4)$ & $295(1)$ & $216(1)$ & $170(2)$ & $3494(130)$ & $285(1)$ \\
\hline
\end{tabular}

* The mean particle size was determined by the equation of $d=K /\left(\rho \times S_{B E T}\right)$, where $K$ is the shape factor, $\rho$ is the density of the material (5.05 $\left.\mathrm{g} / \mathrm{cc}\right)$. and $\mathrm{S}_{B E T}$ is the specific surface area of the material

** Crystal size was determined using Scherrer equation $d=K \lambda /(B \cos \theta)$, where $d$ is the mean crystallite size in volume-weight, $\lambda$ is the wavelength of the $X$-rays, $B$ is the width of a peak at a half maximum due to size effects assuming that there is no strain, $\mathrm{K}$ is a constant value of 0.89 , and $\theta$ is the incident angle

*** Particle sizes were obtained after $1 \mathrm{~h}$ of ball milling 

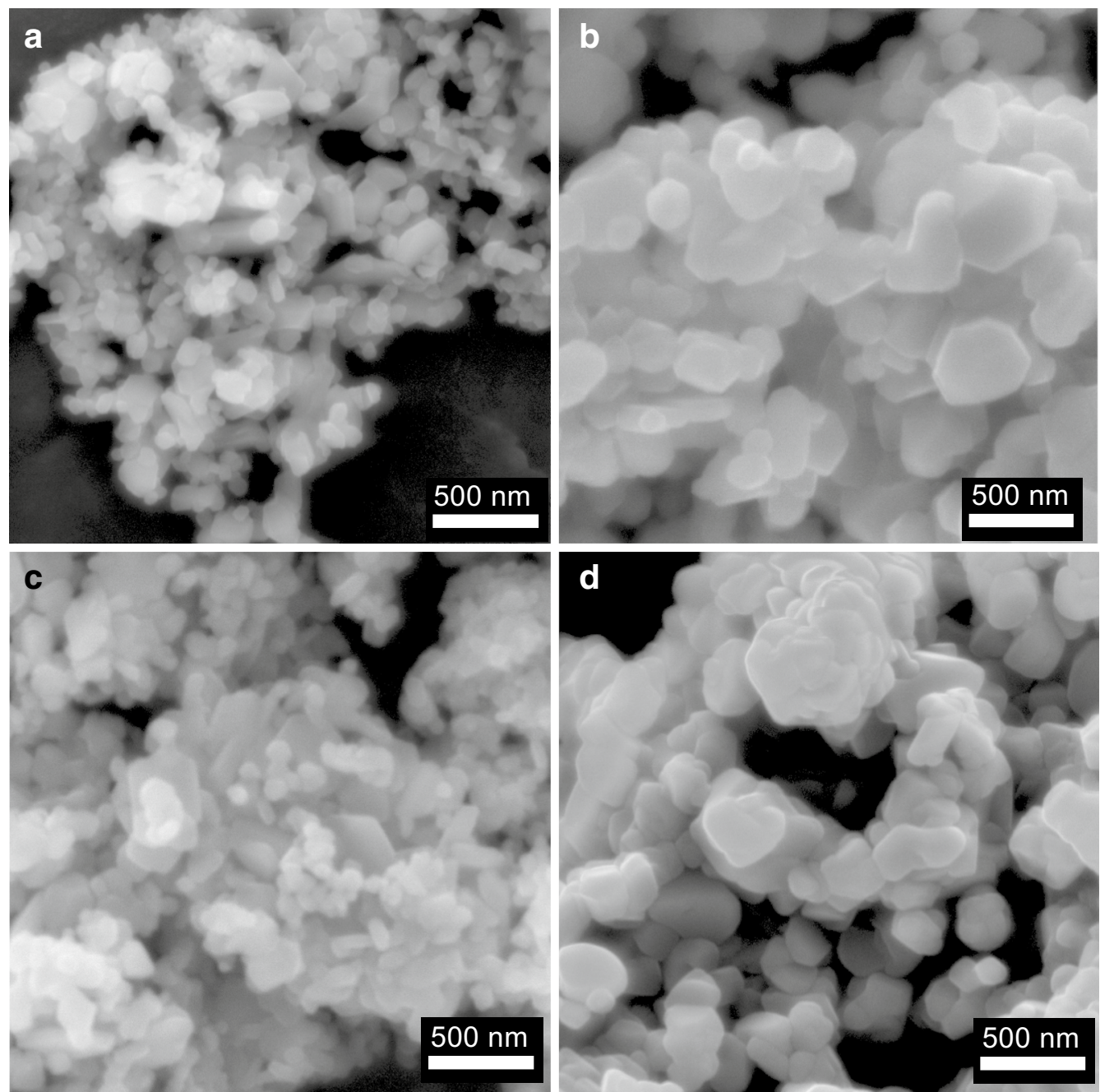

Fig. 11 SEM images of $\mathrm{LiCoO}_{2}$ materials prepared with $\mathrm{LiO}^{t} \mathrm{Bu}(\mathbf{a}), \mathrm{LiO} P \mathrm{Pr}(\mathbf{b}), \mathrm{LiOMe}(\mathbf{c}), \mathrm{LiOPh}(\mathbf{d})$ annealed at $600{ }^{\circ} \mathrm{C}$

The equilibrium charge/discharge curves of the $\mathrm{LiCoO}_{2}$ electrodes obtained from $\mathrm{LiOPh}, \mathrm{LiO}^{t} \mathrm{Bu}$ and $\mathrm{LiOMe}$ precursors were investigated as shown in Fig. 15. The markers are measured when the current is not applied to the battery while the dashed lines are recorded when the current is applied. They show the plateau of equilibrium charge curves at $3.9 \mathrm{~V}$ and discharge at $3.8 \mathrm{~V} \mathrm{vs.} \mathrm{Li}^{+} / \mathrm{Li}$. The coulombic efficiency of the $\mathrm{LiCoO}_{2}$ electrodes from LiOPh reached $>95 \%$ with relatively low polarization between charge and discharge process (Fig. 15a). In case of the $\mathrm{LiCoO}_{2}$ electrode from $\mathrm{LiO}^{t} \mathrm{Bu}$ (Fig. 15b), the coulombic efficiency reached also $>95 \%$ but both charge and discharge processes result in half of the capacities compared to these of the electrodes from LiOPh. Moreover, the potentials during charging with the applied current (dashed lines on the graphs) are higher in Fig. 15b compared to these in Fig. 15a, c.
The deep discharge process was evaluated to estimate how fast the battery can reach the maximum discharge capacity of the different $\mathrm{LiCoO}_{2}$ electrodes. Figure 16 exhibits that the $\mathrm{LiCoO}_{2}$ electrode from $\mathrm{LiOPh}$ precursor, (a), can reach $99 \%$ of its maximum capacity $(120 \mathrm{mAh} / \mathrm{g})$ within $9 \mathrm{~min}$ (at 5.2 C) due to the fast kinetic reaction of $\mathrm{Li}^{+}$ion insertion/extraction. Of course, this maximum capacity remained at any lower current densities, showing the plateau on the right side in Fig. 16a. On the other hand, the electrode from $\mathrm{LiO}^{i} \mathrm{Pr}$ precursor, (b), can be discharged to $90 \%$ of its maximum capacity $(122 \mathrm{mAh} / \mathrm{g})$ at much lower current density of $0.44 \mathrm{C}$ (about $26 \mathrm{~min}$ ) than (a). (b) can reach $85 \%$ (104 $\mathrm{mAh} / \mathrm{g})$ of its maximum discharge capacity within 6 min (at $7 \mathrm{C}$ ). Thus, this deep discharge measurement supports that the discharge capacities at higher current densities $(>\mathrm{C} / 2)$ are lower in $\mathrm{LiCoO}_{2}$ electrode with $\mathrm{LiOPh}$ than those in $\mathrm{LCO}$ with 


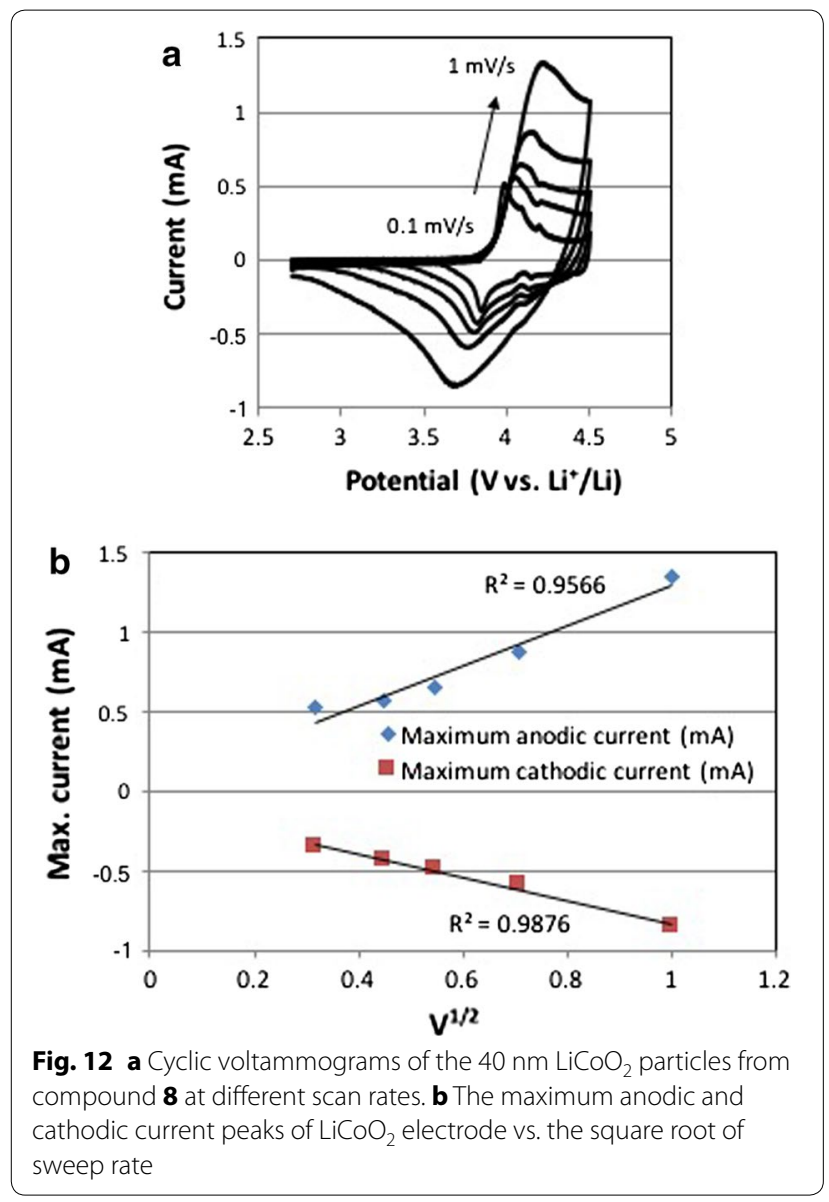

Table 5 Size and Li-ion diffusion coefficient comparison between two precursors, 8 and 12, and HT-LCO Ref. [64]

\begin{tabular}{lll}
\hline Compounds/precursors & Size & $\mathbf{D}_{\mathbf{L i}}\left(\mathbf{c m}^{\mathbf{2}} \mathbf{s}^{\mathbf{1}}\right)$ \\
\hline HT-LCO [64] & $11 \mu \mathrm{m}$ & $2 \times 10^{-7}$ \\
$\mathbf{8}$-LiOtBu & $40 \mathrm{~nm}$ & $2.3 \times 10^{-5}$ \\
$\mathbf{1 2}$-LiOMe & $15 \mathrm{~nm}$ & $4.5 \times 10^{-6}$ \\
\hline
\end{tabular}

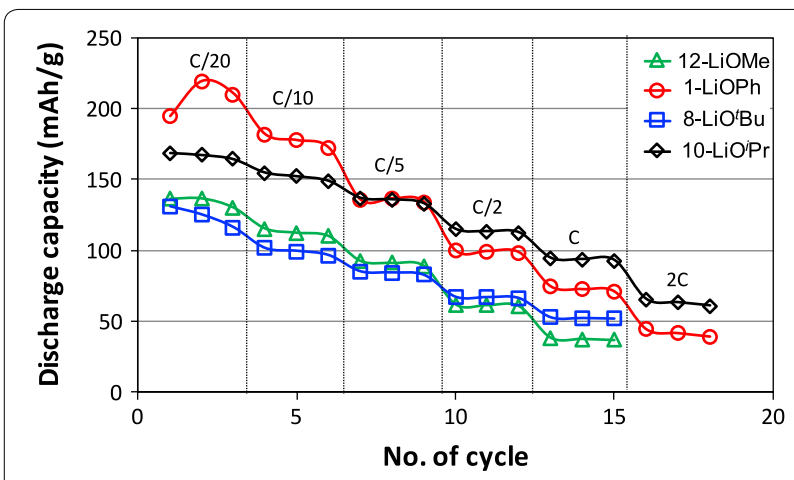

Fig. 13 Discharge capacities of $\mathrm{LiCOO}_{2}$ electrode. $\mathrm{LiCoO}_{2}$ materials were prepared by $\mathbf{8}$-LiO ${ }^{t} \mathrm{Bu}, \mathbf{1 0}$-LiO'Pr, 12-LiOMe and 1-LiOPh

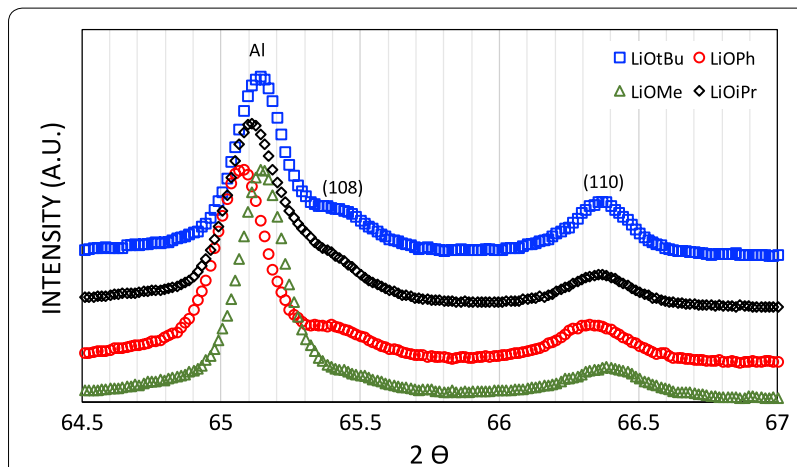

Fig. $14 X R D$ of $\mathrm{LiCoO}_{2}$ electrodes after cycling. $\mathrm{LiCoO}_{2}$ materials were prepared with different precursors: 8 -LiO'Bu (square), 10-LiO'Pr

( $)$, 12-LiOMe (triangle) and 1-LiOPh (circle) precursors; the aluminum peak stems from the current collector of the electrode

$\mathrm{LiO}^{i} \operatorname{Pr}$ (Fig. 16). Therefore, the kinetics of the electrode (a) obtained from $\mathrm{LiO}^{i} \mathrm{Pr}$ is an order of magnitude faster than (b) (obtained from LiOPh) at high current densities.

The Nyquist plots presented for electrodes with different precursors were obtained in the frequency range of $100 \mathrm{kHz}-0.01 \mathrm{~Hz}$ at $25^{\circ} \mathrm{C}$ (Fig. 17). The EIS spectra of the electrodes with $\mathrm{LiOPh}$ and LiOMe precursors are similar in shape with one semicircle and Warburg branch, while the electrode obtained from $\mathrm{LiO}^{t} \mathrm{Bu}$ precursor shows hodographs with two semicircles without Warburg impedance. After fitting the EIS data, the equivalent circuit models were proposed (Additional file 1: Figure S11).

The ion transfer resistance and total impedance of electrodes with different precursors increase in the following sequence: $\mathrm{LiOPh}<\mathrm{LiOMe}<\mathrm{LiO}^{t} \mathrm{Bu}$, which is in good agreement with the discharge capacities and equilibrium charge/discharge curves.

\section{Hazard assessment of particles Particle aerosolisation}

Nanoparticles obtained from precursor 8, which was annealed at $600{ }^{\circ} \mathrm{C}$ for $1 \mathrm{~h}$, were compared to a commercially obtained, micron-sized $\mathrm{LiCoO}_{2}$ sample. A dry powder insufflator was used to aerosolise both materials for direct deposition onto the surface of the multicellular epithelial tissue barrier model. Initially, following aerosolisation, the deposition of the two particle types was characterised in terms of their mass deposition, particle size, as well as their distribution and morphology.

The cell-delivered dose was monitored using an integrated quartz crystal microbalance (QCM) and showed a dose-dependent deposition of the both samples, i.e. $0.81 \pm 0.2,0.55 \pm 0.14$ and $0.16 \pm 0.05 \mu \mathrm{g}$ for nanoparticles, and $3.92 \pm 0.78,1.46 \pm 0.63$ and $0.51 \pm 0.18 \mu \mathrm{g}$ for microparticles. It was, however, not possible to achieve the same range of deposited concentrations for both 

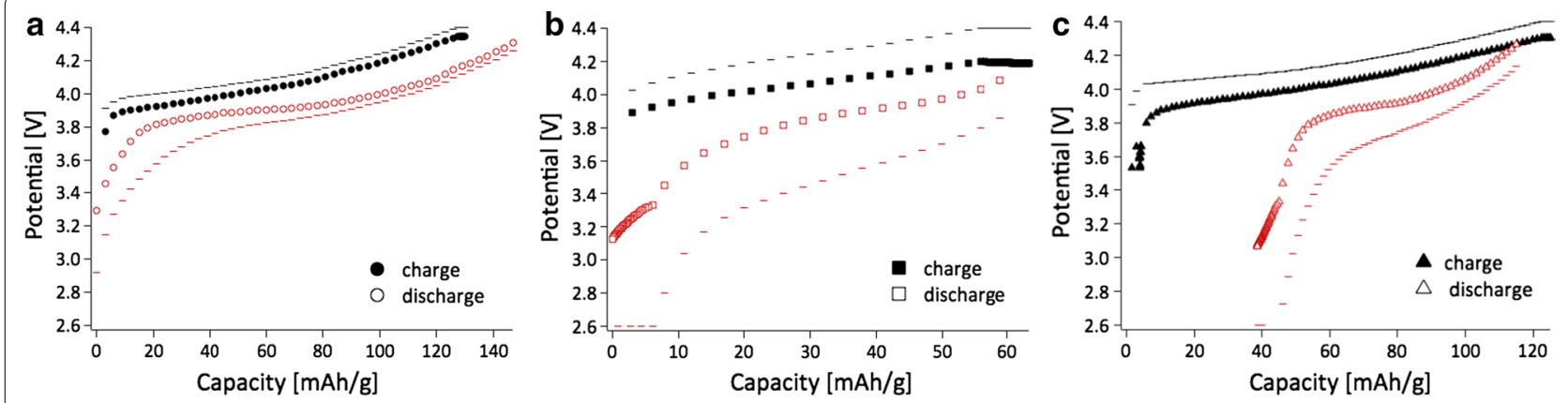

Fig. 15 Charge (filled markers) and discharge (empty markers) curves of $\mathrm{LiCOO}_{2}$ electrodes prepared with filled circle, open circle - LiOPh (a), filled square, open square - $\mathrm{LiO}^{\mathrm{t}} \mathrm{Bu}(\mathbf{b})$, filled triangle, open triangle - $\mathrm{LiOMe}(\mathbf{c})$ precursors. Lines (-) correspond to the potentials with applied current and markers to the potentials without current (in equilibrium state)
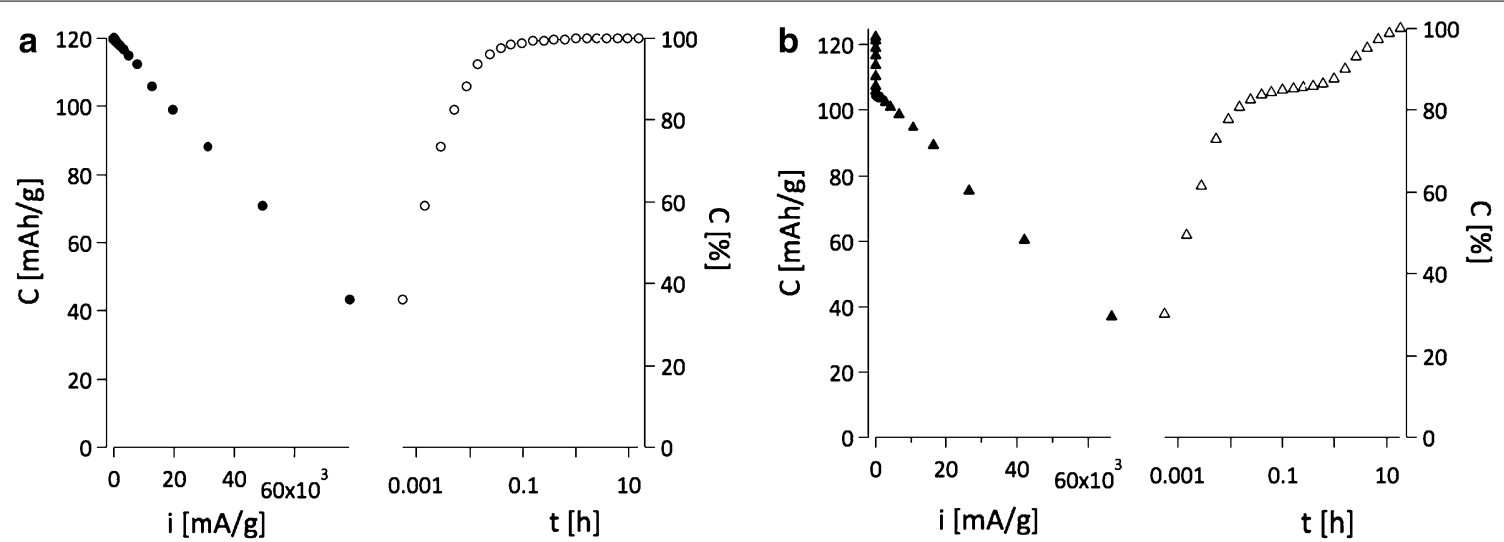

Fig. 16 Deep discharge curves for electrodes obtained from: a LiOPh (filled circle, open circle) and $\mathbf{b}$ LiO'Pr (filled triangle, open triangle) Right axes indicate the state of discharge in percentage (empty markers)
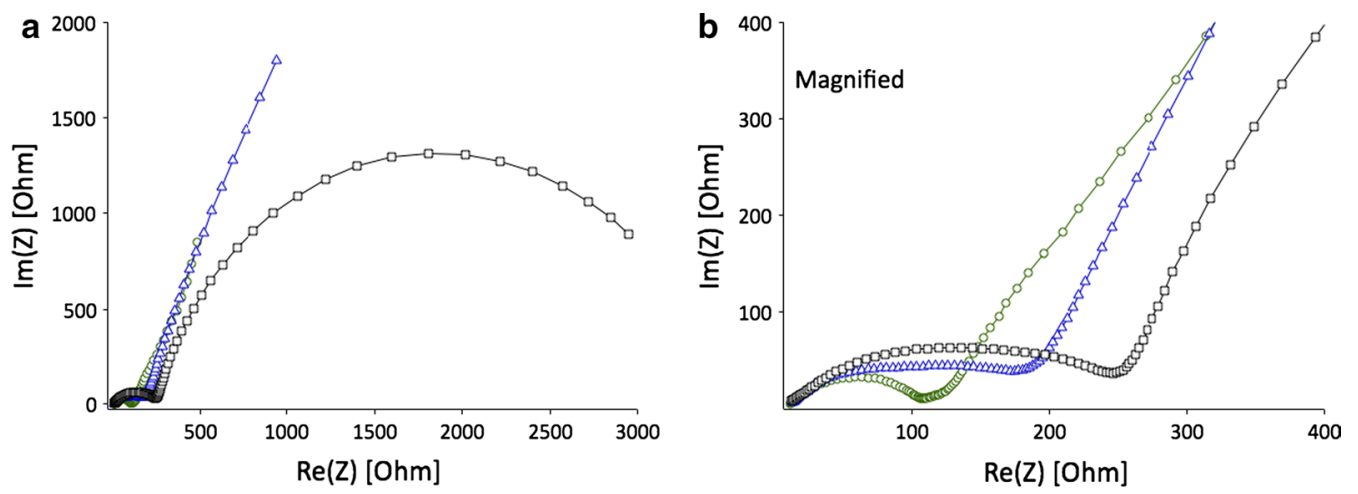

Fig. 17 a Nyquist plots of coin cells consisting of $\mathrm{LiCoO}_{2}$ electrodes with different precursors: square-O' $\mathrm{O}^{t} \mathrm{Bu}$, triangle-OMe, circle-OPh. b Magnified Nyquist plots of (a) 
nano- and micron-sized particles despite using the same initial feed concentration, as shown in Fig. 18a. Reason for this, apart from the different pulverisation methods, is that the microparticles can be considered to exhibit a higher density, and therefore greater tendency to agglomerate/aggregate leading to a higher surface density compared to the limited agglomeration/aggregation shown by the nanoparticles.

By using TEM it was observed that the pulverized nanoparticles of LCO formed agglomerates/aggregates ranging from nano-sized to micron-sized (ca. 0.05$50 \mu \mathrm{m})$. This could possibly be attributed to the low surface charge of the material (i.e. $\leq \pm 10 \mathrm{mV}$ ). The average size of primary nanoparticles was estimated to be $64 \pm 5 \mathrm{~nm}$, as determined by the BET method, while the crystallite size was determined to be $60 \pm 5 \mathrm{~nm}$ using the Scherrer equation. The micron-sized particles were noted to exhibit a size of $10-12 \mu \mathrm{m}$, as previously reported [16-21]. In terms of their morphology, nanoparticles were observed to show rhombohedral/tetrahedral shaped

a

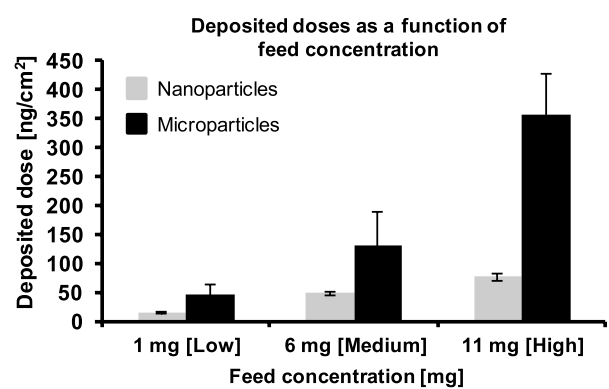

b

Nanoparticles

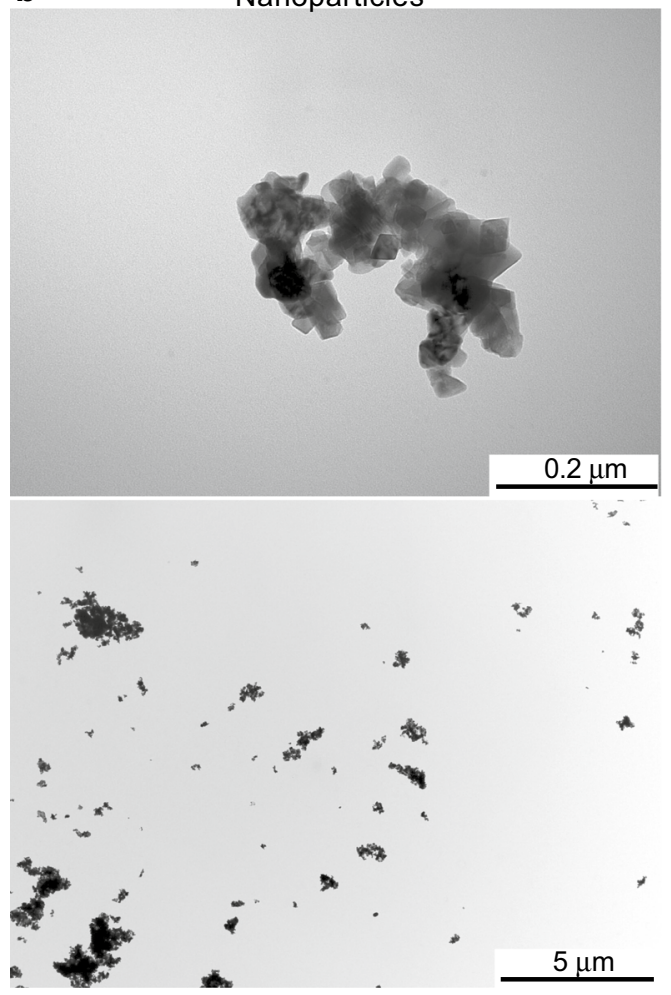

Microparticles

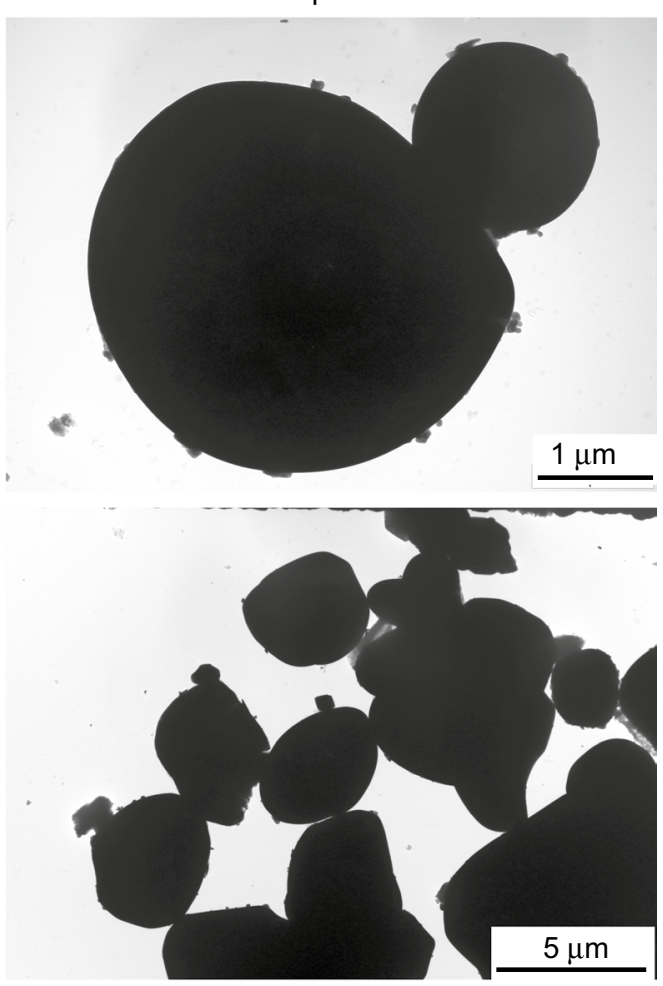

Fig. 18 Deposition characterization of aerosolised nano-sized and micron-sized particles. a Average mass deposition (ng/ $\mathrm{cm}^{2}$ ) of particles quantified using a quartz crystal microbalance (QCM) following nebulisation of low (1 mg), medium (6 mg) and high (11 mg) particle doses using a dry powder insufflator. Data are presented as the mean \pm standard error of the mean. $\mathbf{b}$ Transmission electron micrographs of aerosolized nano- (left) and microparticles (right), indicating, in a qualitative manner, the heterogeneity of the particle deposition for each particle-size. Images also show a representative overview of the particle morphology following the aerosolisation process 
patterns, whereas the commercial microparticles were found to be irregular in shape, with most showing roundish shapes (Fig. 18b).

\section{Cell death}

After $24 \mathrm{~h}$ exposure, $\mathrm{LiCoO}_{2}$ nanoparticles showed limited ability to cause cell death following their aerosolisation onto the in vitro multicellular epithelial tissue barrier model at each particle concentration tested (Fig. 19a). Both low and medium nanoparticle concentrations showed similar effects, whilst the highest concentration applied increased the level of cell death by $50 \%$ compared to the lower concentrations studied. This result can be attributed to an 'overload' scenario upon the cells at the highest concentration applied (Fig. 19b) [65]. It is important to note that although these values are significantly different from the negative control $(p>0.05)$ (i.e. cell culture media only), with the highest concentration applied showing a maximum of $<15 \%$ cell death in the in vitro co-culture system, the findings indicate that the nanoparticles are not causing complete destruction of the cellular system but do induce a limited cytotoxic effect at these concentrations. Similar results were also evident following micron-sized $\mathrm{LiCoO}_{2}$ particle exposures at each test concentration (Fig. 19a). In respect to these semi-quantitative results, it is also important to highlight that qualitative assessment, via confocal laser scanning microscopy, showed no morphological changes to the multicellular system following exposure to either particle type at the highest concentration applied for $24 \mathrm{~h}$ (Fig. 19b).

\section{(Pro-)inflammatory response}

No significant (pro-)inflammatory response (i.e. either TNF- $\alpha$ and IL- 8 release) was observed following nanoparticle exposures across all concentrations tested (Fig. 20). Similar results were observed with the micronsized particles in terms of the TNF- $\alpha$ response from the multicellular system after $24 \mathrm{~h}$ exposure. However, microparticle exposures did show a significant increase $(p>0.05)$ in terms of the IL- 8 response from the co-culture, in a concentration-dependent manner at this time point (Fig. 20).

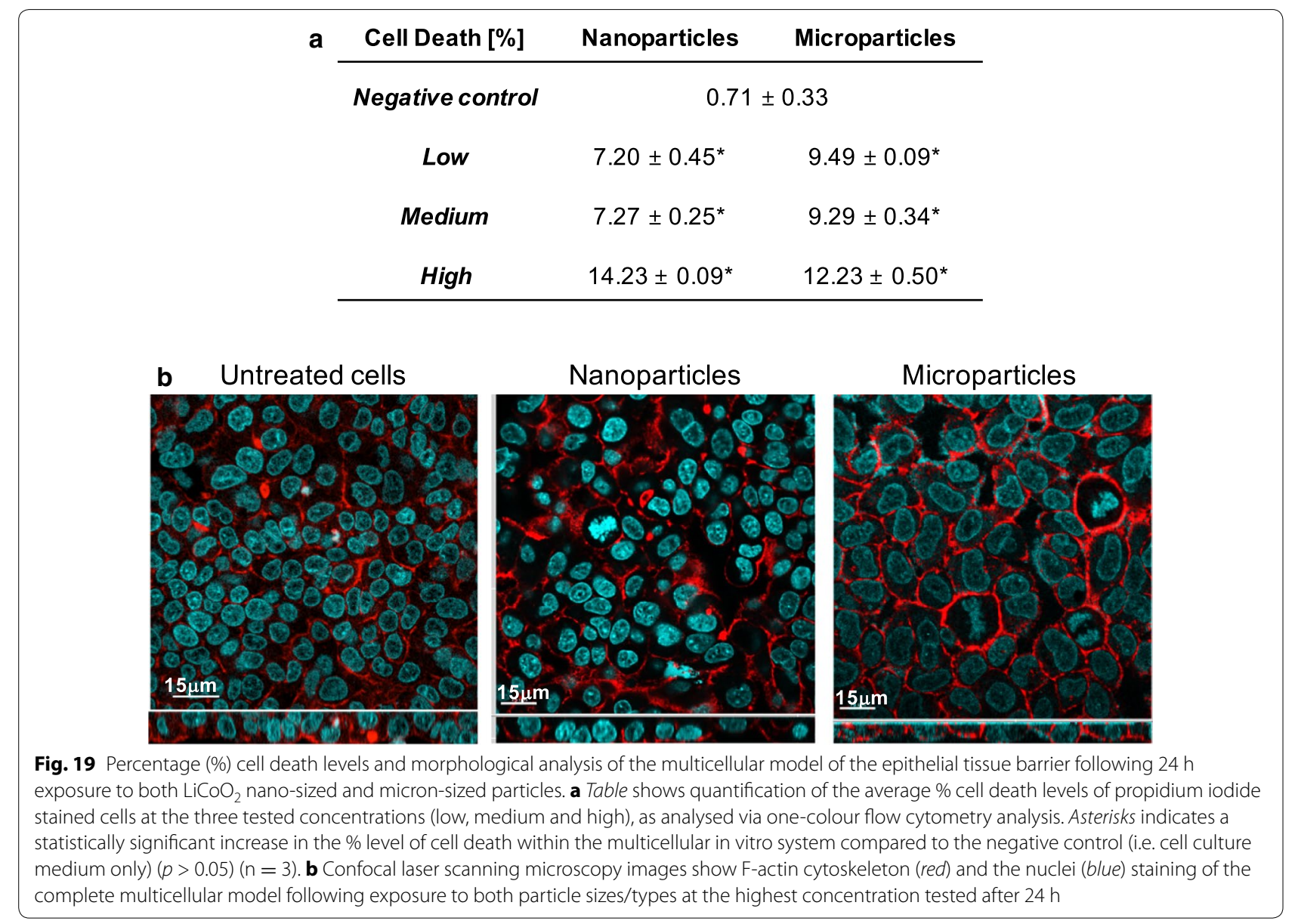




\section{Discussion}

The general reaction of $\mathrm{CoCl}_{2}$ and $\mathrm{LiOPh}$ for the generation of the precursors 1-7 is based on the LiCl-elimination and the formation of a mixed phenoxide with always the same metal ion ratio of 2:1 for $\mathrm{Li}: \mathrm{Co}$, as found in the core $\left[\mathrm{Li}_{2} \mathrm{Co}(\mathrm{OPh})_{4}\right]$ of the structures $1-7$. The formation of this type of compound is in our hands independent of the amount of LiOPh added (between 1 and 6 equivalents). The core is always made of a central $\mathrm{Co}^{2+}$ ion which is surrounded in a (more or less distorted) tetrahedral way by four phenoxide ligands. Two by two, these O-donors act each as $\mu$-bridging ligands to one $\mathrm{Li}^{+}$ion. The coordination sphere of the latter is then completed by either mono- or bidentate donor molecules stemming from the solvent. These coordinated solvent molecules influence the arrangement of the complexes with respect to each other. For instance, 0-dimensional compounds are obtained with monodentate terminal ligands like THF and pyridine or bidentate terminal ligands like DME and TMEDA, whereas bridging ligands such as dioxane lead to polymeric arrangements. In the $\left[\mathrm{Li}_{2} \mathrm{Co}(\mathrm{OPh})_{4}\right]$ cores (Fig. 21) of all compounds 1-5, for which the single crystal structures could be determined to satisfaction, the $\mathrm{Co}-\mathrm{O}$ distances are between 1.938(4) and 1.978(4) $\AA$ long, while the angles $\mathrm{O} 1-\mathrm{Co}-\mathrm{O} 2$ and $\mathrm{O} 3-\mathrm{Co}-\mathrm{O} 4$ are very similar with $86^{\circ}\left( \pm 1^{\circ}\right)$. The $\mathrm{O} 2-\mathrm{Co}-\mathrm{O} 3$ and $\mathrm{O} 1-\mathrm{Co}-$ $\mathrm{O} 4$ angles are however more sensitive to the environment of the $\mathrm{Li}^{+}$cations (see Table 6), respectively packing effects, and vary between 112 and $127^{\circ}$.

The difference of composition between $\mathbf{1}$ and $\mathbf{2}$ originates from the crystallization technique. Indeed, $\mathbf{1}$ is prepared at room temperature with the addition of heptane for crystallization, while $\mathbf{2}$ is crystallized without any co-solvent at $-24{ }^{\circ} \mathrm{C}$. These two different methods give two different products: one thermodynamic compound 1 and one kinetic compound 2 , which can be considered as solvates to each other [66].

In the structure of the compounds $\mathbf{1}$ to 7 , an inherent stoichiometric ratio of two $\mathrm{Li}^{+}$for one $\mathrm{Co}^{2+}$ exists, hence excess of one equivalent $\mathrm{Li}^{+}$with respect to the desired $\mathrm{LiCoO}_{2}$. During the firing, this excess of $\mathrm{Li}^{+}$in the precursor tends to form lithium carbonate either by reaction with the $\mathrm{CO}_{2}$ in air or with the byproducts of the combustion. The carbonate can clearly be seen in powder X-ray diffractogram of the raw oxide. However, these impurities, as well as the main byproduct $\mathrm{LiCl}$ (formation of the precursors), can be easily washed away with water. Successful removal of $\mathrm{LiCl}$ was confirmed by powder $\mathrm{X}$-ray diffraction as well as TEM/SEM.

For the compounds 8-12, except 11, the stoichiometric ratio is $1: 1$ for $\mathrm{Li}^{+}$to $\mathrm{Co}^{2+}$, thus there is no excess $\mathrm{Li}^{+}$and hence almost no formation of lithium carbonate

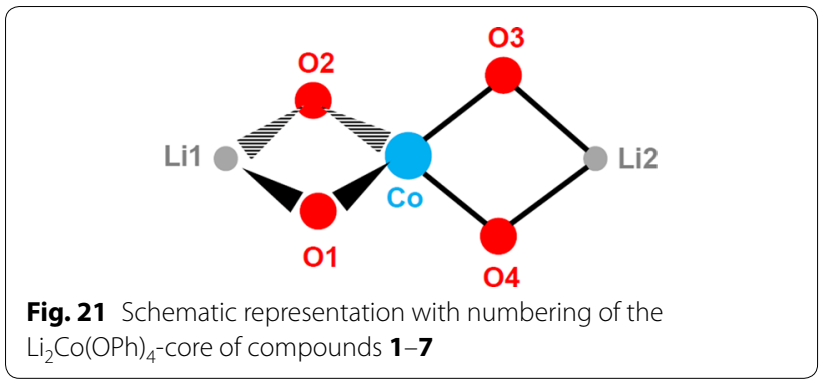

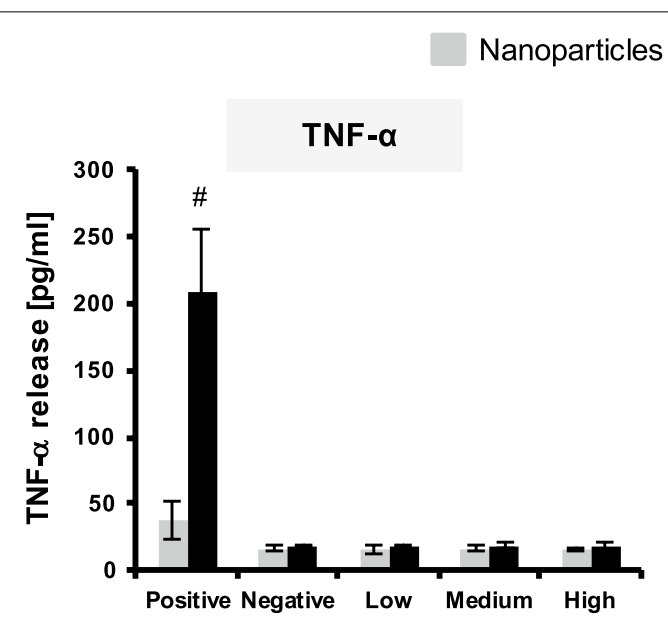

Microparticles

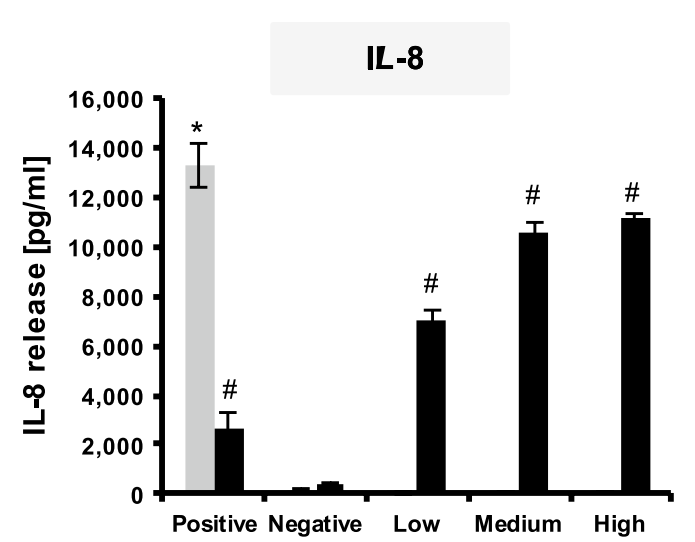

Fig. 20 (Pro-)inflammatory response of the multicellular epithelial tissue barrier following $24 \mathrm{~h}$ exposure to nano-sized and micron-sized nanoparticles at the three different test concentrations. Graphs show the results for the specific (pro-)inflammatory mediators chosen; tumor necrosis factor-a (TNF-a) and interleukin-8 (IL-8). Lipopolysaccharide ([100 $\mu \mathrm{l} \mathrm{of} 1 \mu \mathrm{g} / \mathrm{ml}]$ ) served as the positive assay control, whilst the negative control was cell culture medium only. Data is presented as the mean \pm standard error of the mean. "indicates a statistically significant response $(p>0.05)$ compared to the negative control 
(Additional file 1). While we produced our nanoscale materials in quite pure form by this washing step, the analysis of the commercial HT- $\mathrm{LiCoO}_{2}$ shows that it contains some $\mathrm{Li}_{2} \mathrm{CO}_{3}$ impurities, which is one of the reactants of its synthesis.

The main physical/chemical differences in the final oxides obtained at $450{ }^{\circ} \mathrm{C}$ from $\mathbf{1}$ and $\mathbf{8 - 1 2}$ are the amount of impurities due to stoichiometric reasons and the size of the particles/crystallites obtained. Indeed, the $\mathrm{LiOPh}$ precursor 1 tends to form more impurities (carbonates, XRD in Additional file 1: Fig. S7) and a larger crystallite size. The amount of impurity is mainly due to the incorrect stoichiometric ratio in the starting structure of 2:1 for Li:Co, but also to a large amount of carbon atoms in the precursor. However, by decreasing the number of carbon atoms using alkoxide and by balancing the ratio between $\mathrm{Co}$ and $\mathrm{Li}$ to $1: 1$, better results in terms of size and smaller amounts of byproducts can be achieved. As shown in the Table 4, sizes as low as $60 \mathrm{~nm}$ of HTLCO can be obtained.

We observed different LCO morphologies from the single source precursors. This could be related to the formation of LCO nuclei, which likely depend on the initial structure of the complex precursor. Not only the core structure, but also the arrangement of the molecules with respect to each other may play a role in the formation of different nuclei.

The redox potentials indeed confirm that the obtained nano- $\mathrm{LiCoO}_{2}$ is in the HT-LCO phase. We also recognized that the oxidation of $\mathrm{Co}^{3+}$ to $\mathrm{Co}^{4+}$ (corresponding to $\mathrm{Li}^{+}$extraction from $\mathrm{Li}_{1-\mathrm{x}} \mathrm{CoO}_{2}$ ) shows higher current than the reduction of $\mathrm{Co}^{4+}$ to $\mathrm{Co}^{3+}\left(\mathrm{Li}^{+}\right.$insertion into $\mathrm{Li}_{1-x} \mathrm{CoO}_{2}$ ). The cyclic voltammograms (CV) of both samples obtained from $\mathbf{1 2}$ and $\mathbf{8}$ show a HT-LCO $\mathrm{CV}$ profile with a low polarization and high potential, as expected from the X-ray diffraction pattern.

In terms of the $\mathrm{Li}^{+}$diffusivity, hence the kinetic with respect to $\mathrm{Li}^{+}$ions, we found it to be much faster in nanoscale LCO than in micron-LCO. In other words, the amount of $\mathrm{Li}^{+}$ions available for electrochemistry is larger in nanoscale LCO than that in micron-LCO due to the shorter path length of the $\mathrm{Li}^{+}$ion diffusion. The values obtained are $>20$ times higher than the standard value for HT-LCO [64]. In the best case measured in our hands, $77 \%$, of all $\mathrm{Li}^{+}$ions were extracted from and re-inserted in the structure of nano-HT-LCO, while for the com-

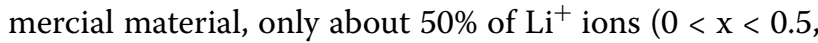
$\mathrm{Li}_{1-x} \mathrm{CoO}_{2}$ ) can be used electrochemically in the rhombohedral layered structure of $\mathrm{LiCoO}_{2}$. Further de-lithiation of commercial, micro-HT-LCO induces a phase transformation to the monoclinic system [17], resulting in irreversible capacity loss upon cycling. Therefore, the phase stability of $\mathrm{LiCoO}_{2}$ is important during lithiation and de-lithiation in order to obtain high coulombic efficiency and longer cycleability of battery. This is what we could show for the nano-HT-LCO after battery cycling by analyzing the material by XRD. Hence, our LCO materials prepared by heterobimetallic single source precursors are stable upon cycling and provide fast electrochemical reactions with $\mathrm{Li}^{+}$ions due to nanosized particles.

Table 6 Comparison of compounds 1 to 5 and 9

\begin{tabular}{|c|c|c|c|c|c|c|c|}
\hline & 1 & 2 & 3 & 4 & & 5 & 9 \\
\hline Tetrahedral volume of Co $\left(\AA^{3}\right)$ & 3.332 & 3.384 & 3.344 & 3.364 & & 3.339 & 3.229 \\
\hline Quadratic elongation & 1.093 & 1.088 & 1.092 & 1.079 & & 1.100 & 1.120 \\
\hline Angle variance $\left({ }^{\circ 2}\right)$ & 378.27 & 360.86 & 374.83 & 322.26 & & 401.40 & 486.42 \\
\hline O1-Co $(\AA)$ & $1.961(6)$ & $1.960(7)$ & $1.95(1)$ & $1.954(3)$ & $1.958(4)$ & $1.954(4)$ & $\begin{array}{l}1.947(3) \\
1.949(3)\end{array}$ \\
\hline $\mathrm{O} 2-\mathrm{Co}(\AA)$ & $1.948(5)$ & $1.957(6)$ & $1.93(1)$ & $1.963(4)$ & $1.955(3)$ & $1.962(4)$ & $1.960(3)$ \\
\hline O3-Co $(\AA)$ & $1.963(5)$ & $1.946(6)$ & $1.961(8)$ & $1.954(3)$ & $1.966(3)$ & $1.978(4)$ & $1.958(4)$ \\
\hline O4-Co $(\AA)$ & $1.972(6)$ & $1.960(6)$ & $1.966(7)$ & $1.952(4)$ & $1.961(4)$ & $1.938(4)$ & / \\
\hline Mean O-Co $(\AA)$ & 1.961 & 1.956 & 1.952 & 1.956 & 1.960 & 1.958 & 1.953 \\
\hline $\mathrm{O} 1-\mathrm{Co}-\mathrm{O} 2\left(^{\circ}\right)$ & $84.9(2)$ & $86.5(3)$ & $85.7(1)$ & $86.8(2)$ & $86.6(2)$ & $85.6(2)$ & $80.2(1)$ \\
\hline $\mathrm{O} 3-\mathrm{Co}-\mathrm{O} 4\left(^{\circ}\right)$ & $86.0(2)$ & $85.2(3)$ & $85.1(4)$ & $87.5(1)$ & $87.0(2)$ & $84.8(2)$ & $83.9(2)$ \\
\hline $\mathrm{O} 1-\mathrm{Co}-\mathrm{O} 4\left(^{\circ}\right)$ & $122.4(2)$ & $121.0(3)$ & $125.6(4)$ & $118.6(1)$ & $122.7(2)$ & $126.5(2)$ & $124.4(2)$ \\
\hline $\mathrm{O} 2-\mathrm{Co}-\mathrm{O} 3\left(^{\circ}\right)$ & $118.4(2)$ & $120.0(3)$ & $123.0(4)$ & $117.6(2)$ & $125.0(1)$ & $112.4(2)$ & $125.2(1)$ \\
\hline Mean O-Co-O $\left(^{\circ}\right)$ & $\begin{array}{l}85.45 \\
120.4\end{array}$ & $\begin{array}{l}85.85 \\
120.5\end{array}$ & $\begin{array}{l}85.4 \\
124.3\end{array}$ & $\begin{array}{l}86.98 \\
120.98\end{array}$ & & $\begin{array}{l}85.2 \\
119.45\end{array}$ & $\begin{array}{l}82.0 \\
124.8\end{array}$ \\
\hline BVS on Co & 1.93 & 1.96 & 1.98 & 1.96 & 1.94 & 1.95 & 1.97 \\
\hline BVS on Li & $\begin{array}{l}1.17 \\
1.14\end{array}$ & $\begin{array}{l}1.13 \\
1.14\end{array}$ & $\begin{array}{l}1.13 \\
1.07\end{array}$ & $\begin{array}{l}1.19 \\
1.17\end{array}$ & $\begin{array}{l}1.13 \\
1.14\end{array}$ & $\begin{array}{l}1.19 \\
1.25\end{array}$ & 1.18 \\
\hline
\end{tabular}


The LCO materials prepared from various complexes showed different specific capacities. This difference may be related to several parameters such as the homogeneity of particle size, ball milling and the shape of LCO particles. Also, when a particle size distribution is broad, the specific capacity can be less good than the one from the narrower size distributed particles. The large size difference can lead to different $\mathrm{Li}^{+}$diffusion kinetics. However, the larger particles can be broken during ball milling and the size distribution becomes narrower, improving the kinetics of $\mathrm{Li}^{+}$diffusion and finally the specific capacity. The shape of LCO particle can also affect the diffusion of $\mathrm{Li}^{+}$because $\mathrm{Li}^{+}$diffuses in a specifically oriented layer of the structure.

The smaller particle size provides higher diffusion kinetics with $\mathrm{Li}^{+}$because the higher surface area of nano- $\mathrm{LiCoO}_{2}$ provides more $\mathrm{Li}^{+}$ions to be released and uptaken into/from the electrolyte. In addition to the high surface area, there is another parameter governing the diffusion kinetics, which is the orientation of $\mathrm{Li}^{+}$diffusion path in the lattice structure of $\mathrm{LiCoO}_{2} . \mathrm{Li}^{+}$is located in one layer of the $\mathrm{LiCoO}_{2}$ lattice cell, diffusing in one preferred orientation. Thus, the length of $\mathrm{Li}^{+}$diffusion path in $\mathrm{LiCoO}_{2}$ also affects the diffusion kinetics. We reported that the diffusion of $\mathrm{Li}^{+}$is not only related to the size of particle but also the shape of particle due to the preferred diffusion direction and its length in the lattice structure $[67,68]$. In this regard, the higher diffusion coefficient of $40 \mathrm{~nm}$ (compound 8) is probably coming from the shorter diffusion path of $\mathrm{Li}^{+}$in a single particle although the compound $\mathbf{1 2}$ has a smaller size of $15 \mathrm{~nm}$.

We also found that $\mathrm{LiCoO}_{2}$ produced from $\mathrm{LiO}^{t} \mathrm{Bu}$ has a larger overpotential and higher resistance than the one obtained from LiOPh. On the other hand, the $\mathrm{LiCoO}_{2}$ electrode formed from LiOMe reached $>120 \mathrm{mAh} / \mathrm{g}$ of charge capacity. However, the discharge capacity was $90 \mathrm{mAh} / \mathrm{g}$ with $70 \%$ of coulombic efficiency. These differences of equilibirum charge/discharge curves can be explained by different kinetics at equilibrium state.

The deep discharge measurement supports that the discharge capacities at higher current densities $(>C / 2)$ are lower in $\mathrm{LiCoO}_{2}$ electrode with $\mathrm{LiOPh}$ than those in $\mathrm{LCO}$ with $\mathrm{LiO}^{i} \mathrm{Pr}$ (Fig. 16). Therefore, the kinetics of the electrode (a) obtained from $\mathrm{LiO}^{i} \mathrm{Pr}$ is an order of magnitude faster than (b) (obtained from LiOPh) at high current densities.

The electrochemical properties of batteries are influenced by not only the active material but also the composite, consisting of carbon and the active material [69]. The structural morphology and the physicochemical properties of composite affect the electron transfer and lithium ion diffusion in the electrode [64]. An ongoing follow-up study is hence the optimization of the electrode composites for each nanoscale HT-LCO material as a function of precursor.

In terms of the biological assessment, such studies had never been done on nanoscale LCO and are quite rare for battery materials in general. We found both nano- and micro-LCO to be relatively low toxic in the lung model which we used. The (pro-)inflammatory response upon exposure to nano-LCO was nil across all tested concentrations, while it was dose-dependent for micro-LCO. Neither nanoparticles nor micro-LCO induce a cytotoxic effect at the tested concentrations which leads to more than $15 \%$ cell death. In terms of the surface charges of nano and microparticles, we estimate it is low since both particles rather stick together [70].

\section{Conclusions}

A series of 12 new precursors containing lithium and cobalt ions in ratios of 2:1 or 1:1 with different aryl- and alkoxide ligands have been prepared and characterized. Their thermal decomposition leads to the formation of nanoscale $\mathrm{HT}-\mathrm{LiCoO}_{2}$ with the size of the so obtained nanoparticles depending on the precursor. Also, precursors with a $1: 1$ ratio of $\mathrm{Li}^{+}$to $\mathrm{Co}^{2+}$ lead to quite pure product, while the precursors with a 2:1 ratio gave $\mathrm{Li}_{2} \mathrm{CO}_{3}$ as byproduct. The use of our precursors allowed lowering the production temperature and time for the generation of $\mathrm{HT}-\mathrm{LiCoO}_{2}$ as a preorganisation of the metal ions takes place in the starting material. The nanomaterials of $\mathrm{LiCoO}_{2}$ showed a superior Li-ion diffusivity by a factor of 20-100 compared to commercial $\mathrm{LiCoO}_{2}$, depending on the precursor used to generate the cathode material. The electrochemical performance was varied depending on the precursors. $\mathrm{LiCoO}_{2}$ with $\mathrm{LiOPh}$ and $\mathrm{LiO}^{i} \mathrm{Pr}$ provided higher specific capacities while $\mathrm{LiCoO}_{2}$ with $\mathrm{LiOMe}$ and $\mathrm{LiOtBu}$ obtained lower specific capacities. Lithium ion diffusion coefficients of our nanoscale $\mathrm{LiCoO}_{2}$ were $>10$ times higher than the one of microscale $\mathrm{LiCoO}_{2}$ due to the shorter path length of lithium ion diffusion in nanomaterial of $\mathrm{LiCoO}_{2}$. This means that high surface area of nanoscale $\mathrm{LiCoO}_{2}$ can release and take $\mathrm{Li}^{+}$ions much more than micron $\mathrm{LiCoO}_{2}$ material at the same condition.

To mimick conditions of recycling of batteries, nanopowders of $\mathrm{LiCoO}_{2}$ were tested on a lung cell model. During the spraying of the powders, it was shown that the nanopowders tend to aggregate during the process due to a low zeta-potential. Nevertheless, they are slightly more toxic than the micron-scale material, while toxicity remained overall very low. 


\section{Additional file}

Additional file1: Text 1. Synthesis of bimetallic compounds. Table S1. Crystal data. Text 2. Single crystal structure descriptions. Text 3. Argentometric titration. Table S2. Idealistic oxidation reactions of two types of compounds, precursors 1, $\mathbf{5}$ with 2:1 and precursors $\mathbf{8 ,}, \mathbf{9}$ with 1:1 stoichiometric ratio between $\mathrm{Li}+$ and $\mathrm{Co} 2+$. Table S3. Results of the argentometric titration of chloride and ICP-measurements for lithium. Table S4. ICP analysis for $\mathrm{Li}+$ and $\mathrm{CO} 3+$ of $\mathrm{LiCOO} 2$ obtained from different precursors. Figure S6. XRD study of commercial LCO, and nano-LCO obtained from LiOtBu before annealing and after annealing at $600^{\circ} \mathrm{C}$ and $700^{\circ} \mathrm{C}$. Figure S7. XRD of LiCoO2 from 9-LiOPh calcined at $450^{\circ} \mathrm{C}$ before washing. The red line corresponds to HT-LCO and the blue lines are Li2CO3. Table S5. The combustion temperature and the thermal measurement conditions of the compounds 1, 8-12. Table S6. TGA weight loss in percentage [\%] with associated steps of compounds 1, 8-12. Equation S1-S5. Determination of the particle and crystallite sizes. Figure S8. Morphologies of $\mathrm{LiCoO} 2$ prepared with different precursors at $450^{\circ} \mathrm{C}$. Figure S9. (a) Cyclic voltammograms of the $15 \mathrm{~nm} \mathrm{LCO}$ prepared from the compound 12 at different sweep rates. (b) The maximum anodic and cathodic current peaks of LiCoO2 electrode versus the square root of sweep rate. Table S7. $\mathrm{Li}+$ diffusion coefficients determined for HT-LCO obtained from different precursors. Figure S10. Nyquist plot for $\mathrm{LiCoO} 2$ electrodes from LiOtBu with fit: filled markers - experimental points, open markers - fit points with error bars a) and corresponding equivalent circuit model b) with fitting report c). Figure S11. Nyquist plot obtained for LiCoO2 electrodes from LiOPh with fit: filled markers - experimental points, open markers fit points with error bars a) and corresponding equivalent circuit model b) with fitting report c).

\section{Abbreviations}

HT-LCO: high temperature $\mathrm{LiCOO}_{2} ;$ LT-LCO: low temperature $\mathrm{LiCoO}_{2}$; THF: tetrahydrofuran; ALI: air-liquid interface; LiOPh: lithium phenoxide; $\mathrm{LiO}^{\mathrm{t}} \mathrm{Bu}$ : lithium tert-butoxide; LiOMe: lithium methoxide; LiOEt: lithium ethoxide; LiO'Pr: lithium iso-propoxide; TMEDA: tetramethylethylenediamine; DME: dimethoxyethane; Py: pyridine; IR: infra-red; NMR: nuclear magnetic resonance; XRD: $X$-ray diffraction; $M$ : molecular mass; $a, b$, c: unit cell dimensions; $\beta$ : monoclinic angle; $V$ : unit cell volume; $Z$ : number of independent asymmetric units per unit cell; $\rho_{\text {calcd: }}$ density; $T$ : temperature at which single crystals were measured; $\Theta$ : theta angle for single crystal $x$-ray measurements; GOOF: goodness of fit; $R 1$, wR2: quality factors; TGA: thermogravimetric analysis; STDA: simultaneous differential thermal analysis; BET: Brunauer, Emmett and Teller; SEM: scanning electron miscroscope; FEl: field electron and ion; EDS: energy dispersive $\mathrm{X}$-ray spectroscopy; ICP-OES: inductively coupled plasma optical emission spectrometry; PVDF: polyvinylidene fluoride; NMP: N-methyl-2-pyrrolidone; ABG and SFG: name of graphite provided from the manufacturer; EC: ethylene carbonate; DMC: dimethyl carbonate; DEC: diethylene carbonate; $\mathrm{C} / 20, \mathrm{C} / 10$, $\mathrm{C} / 5, \mathrm{C} / 2,1 \mathrm{C}$ and 20C: charging for $20 \mathrm{~h}, 10 \mathrm{~h}, 5 \mathrm{~h}, 2 \mathrm{~h}, 1 \mathrm{~h}$ and $3 \mathrm{mins}$; EIS: electrochemical impedance spectroscopy; FRA: frequency response analyser; RPMI: Roswell Park Memorial Institute; PET: polyethylene terephthalate; $\mathrm{CH}$ cluster of differentiation; DP: dry powder insufflator; ELISA: enzyme-linked immunosorbent assay; BVS: bond-valence-sum.

\section{Authors' contributions}

JPB, AC and SM synthesized and characterized the complexes and LCO. BB and MS performed the electrochemistry. AZ proposed the deep discharge analysis. JPB and HB performed the biological assessment with the guidance of MJDC and BRR. NHK guided the characterization, electrochemistry and the manuscript. KMF supervised the project and the manuscript. All authors read and approved the final manuscript.

\section{Author details}

1 Department of Chemistry, University of Fribourg, Chemin du Musée 9, 1700 Fribourg, Switzerland. ${ }^{2}$ Fribourg Center for Nanomaterials FriMat, University of Fribourg, Chemin du Musée 9, 1700 Fribourg, Switzerland. ${ }^{3}$ Adolphe Merkle Institute, University of Fribourg, 1700 Fribourg, Switzerland. ${ }^{4}$ College of Engineering and Architecture of Fribourg, University of Applied Sciences of Western Switzerland, Boulevard de Pérolles 80, 1705 Fribourg, Switzerland. ${ }^{5}$ Laboratory of Materials for Renewable Energy (LMER), ISIC-SB, École Polytechnique Fédérale de Lausanne (EPFL), Valais/Wallis Energypolis, Rue de I'Industrie 17, 1951 Sion, Switzerland.

\section{Acknowledgements}

This study was supported by the Swiss National Science Foundation (National Research Program 64), the Swiss Competence Center for Energy Research (SCCER) Heat and Electricity Storage, the FriMat (the Fribourg Center for Nanomaterials), the NCCR "Bioinspired Materials" and the University of Fribourg.

\section{Competing interests}

The authors declare that there are no competing interests nor commercial interests.

\section{Ethics and others}

Not applicable.

\section{Funding}

This work was supported by the National Research Program 64, Project Number 406440_141604 from the Swiss National Science Foundation.

\section{Publisher's Note}

Springer Nature remains neutral with regard to jurisdictional claims in published maps and institutional affiliations.

Received: 18 January 2017 Accepted: 31 July 2017

Published online: 22 August 2017

\section{References}

1. Mizushima K, Jones PC, Wiseman PJ, Goodenough JB. Li $\mathrm{CoO}_{2}(0<\mathrm{x}<-1)$ : a new cathode material for batteries of high energy density. Mater Res Bull. 1980:15:783-9.

2. Reimers JN, Dahn JR. Electrochemical and in situ X-ray diffraction studies of lithium intercalation in $\mathrm{Li}_{\times} \mathrm{CoO}_{2}$. J Electrochem Soc. 1992;139:2091-7.

3. Ohzuku T, Ueda A. Solid-state redox reactions of $\mathrm{LiCOO}_{2}(\mathrm{R} \overline{3} \mathrm{~m})$ for 4 volt secondary lithium cells. J Electrochem Soc. 1994;141:2972-7.

4. Ménétrier M, Saadoune I, Levasseur S, Delmas C. The insulator-metal transition upon lithium deintercalation from $\mathrm{LiCOO}_{2}$ : electronic properties and 7Li NMR study. J Mater Chem. 1999;9:1135-40.

5. Molenda J, Stoklosa A, Bak T. Modification in the electronic structure of cobalt bronze $\mathrm{Li}_{x} \mathrm{CoO}_{2}$ and the resulting electrochemical properties. Solid State lonics. 1989;36:53-8

6. Van der Ven A, Aydinol MK, Ceder G. First principles evidence for stage ordering in $\mathrm{Li}_{x} \mathrm{CoO}_{2}$. J Electrochem Soc. 1998;145:2149-55.

7. Van der Ven A, Aydinol MK, Ceder G, Kresse G, Hafner J. First-principles investigation of phase stability in $\mathrm{Li}_{x} \mathrm{CoO}_{2}$. Phy Rev B. 1998;58:2975-87.

8. Amatucci GG, Tarascon JM, Klein LC. $\mathrm{CoO}_{2}$, the end member of the $\mathrm{Li}_{x} \mathrm{CoO}_{2}$ solid solution. J Electrochem Soc. 1996;143:1114-23.

9. LiW, Reimers JN, Dahn JR. Lattice-gas-model approach to understanding the structures of lithium transition-metal oxides $\mathrm{LiMO}_{2}$. Phy Rev B. 1994;49:826.

10. Huang W, Frech R. Vibrational spectroscopic and electrochemical studies of the low and high temperature phases of $\mathrm{LiCO}_{1-x} \mathrm{MxO}_{2}(\mathrm{M}=\mathrm{Ni}$ or Ti). Solid State Ion. 1996;86-88:395-400.

11. Antolini E. LiCoO 2 : formation, structure, lithium and oxygen nonstoichiometry, electrochemical behaviour and transport properties. Solid State Ion. 2004;170(3-4):159-71. doi:10.1016/j.ssi.2004.04.003.

12. Gummow RJ, Thackeray MM, Wif D, Hull S. Structure and electrochemistry of lithium cobalt oxide synthesised at $400^{\circ} \mathrm{C}$. Mater Res Bull. 1992:27:327-37.

13. Garcia B, Farcy J, Pereira-Ramos JP, Baffier N. Electrochemical properties of low temperature crystallized $\mathrm{LiCoO}_{2}$. J Electrochem Soc. 1997;144:1179-84.

14. Rossen E, Reimers JN, Dahn JR. Synthesis and electrochemistry of spinel LT-LiCoO 2 . Solid State Ion. 1993;62:53-60. 
15. Orman HJ, Wiseman PJ. Cobalt(III) lithium oxide, $\mathrm{CoLiO}_{2}$ : structure refinement by powder neutron diffraction. Acta Crystallogr C. 1984;40:12-4.

16. Garcia B, Farcy J, Pereira-Ramos JP, Perichon J, Baffler N. Low-temperature cobalt oxide as rechargeable cathodic material for lithium batteries. J Power Sources. 1995;54:373-7.

17. Shao-Horn Y, Croguennec L, Delmas C, Nelson EC, O'Keefe MA. Atomic resolution of lithium ions in $\mathrm{LiCoO}_{2}$. Nat Mater. 2003;2(7):464-7.

18. Kim J, Fulmer P, Manthiram A, Kim J, Fulmer P, Manthiram A. Synthesis of $\mathrm{LiCOO}_{2}$ cathodes by an oxidation reaction in solution and their electrochemical properties. Mater Res Bull. 1999;34(4):571-9.

19. Myung ST, Kumagai N, Komaba S, Chung HT. Preparation and electrochemical characterization of $\mathrm{LiCOO}_{2}$ by the emulsion drying method. J Appl Electrochem. 2000;30(9):1081-5.

20. Yoshio M, Tanaka H, Tominaga K, Noguchi $\mathrm{H}$. Synthesis of $\mathrm{LiCoO}_{2}$ from cobalt_-organic acid complexes and its electrode behaviour in a lithium secondary battery. J Power Sources. 1992;40:347-53.

21. Antolini $\mathrm{E}$. Lithium loss from lithium cobalt oxide: hexagonal $\mathrm{Li}_{0.5} \mathrm{CO}_{0.5} \mathrm{O}$ to cubic $\mathrm{Li}_{0.065} \mathrm{CO}_{0.935} \mathrm{O}$ phase transition. Int J Inorg Mater. 2001;3:721-6.

22. Oh $\mathrm{H}$, Hong SA, Sun YK. Low-temperature preparation of ultrafine $\mathrm{LiCOO}_{2}$ powders by the sol-gel method. J Mater Sci. 1997;32(12):3177-82.

23. Yoon WS, Kim KB. Synthesis of $\mathrm{LiCoO}_{2}$ using acrylic acid and its electrochemical properties for Li secondary batteries. J Power Sources. 1999;81-82:517-23

24. Peng ZS, Wan CR, Jiang CY. Synthesis by sol-gel process and characterization of $\mathrm{LiCOO}_{2}$ cathode materials. J Power Sources. 1998;72(2):215-20.

25. Sun $\mathrm{YK}, \mathrm{Oh} H \mathrm{H}$, Hong SA. Synthesis of ultrafine $\mathrm{LiCOO}_{2}$ powders by the sol-gel method. J Mater Sci. 1996:31(14):3617-21.

26. Burukhin A, Brylev O, Hany P, Churagulov BR. Hydrothermal synthesis of $\mathrm{LiCOO}_{2}$ for lithium rechargeable batteries. Solid State lon. 2002;151:259-63.

27. Fromm KM. Synthesis and crystal structure of $\mathrm{Li}\left[\left\{\mathrm{Ca}_{7}\left(\mathrm{U}_{3}-\mathrm{OH}\right)_{8} I_{6}(\mathrm{thf})_{12}\right\}_{2}(\mathrm{u}-\right.$ I)].3THF, a unique $\mathrm{H}$-bound dimer of a $\mathrm{Ca}_{7}$-cluster on the way to sol-gels. Chem Commun. 1999:17:1659-60.

28. Fromm KM, Gueneau ED, Goesmann H. Synthesis and crystal structure of $\left[\mathrm{IBa}(\mathrm{OBut})_{4}\{\mathrm{Li}(\mathrm{thf})\}_{4}(\mathrm{OH})\right]$ : a mixed ligand heterometallic cluster with an unusual low coordination number for barium. Chem Commun. 2000;22:2187-8. doi:10.1039/b005638n.

29. Fromm KM, Gueneau ED, Bernardinelli G, Goesmann H, Weber J, MayorLópez MJ, et al. Understanding the formation of new clusters of alkali and alkaline earth metals. J Am Chem Soc. 2003;125(12):3593-604.

30. Maudez W, Häussinger D, Fromm KM. A Comparative study of (Poly) ether adducts of alkaline earth iodides - an overview including new compounds. Z Anorg Allg Chem. 2006;632(14):2295-8.

31. Maudez W, Meuwly M, Fromm KM. Analogy of the coordination chemistry of alkaline earth metal and lanthanide $\mathrm{Ln}^{2+}$ Ions: the isostructural zoo of mixed metal cages [IM (OtBu) $\left.{ }_{4}\{\mathrm{Li}(\mathrm{thf})\}_{4}(\mathrm{OH})\right](\mathrm{M}=\mathrm{Ca}, \mathrm{Sr}, \mathrm{Ba}, \mathrm{Eu}),\left[\mathrm{MM}_{6}^{\prime}\right.$ $\left.(\mathrm{OPh})_{8}(\mathrm{thf})_{6}\right]\left(\mathrm{M}=\mathrm{Ca}, \mathrm{Sr}, \mathrm{Ba}, \mathrm{Sm}, \mathrm{Eu}, \mathrm{M}^{\prime}=\mathrm{Li}, \mathrm{Na}\right)$, and their derivatives with 1,2- Dimethoxyethane. Chem Eur J. 2007:13:8302-16.

32. Gschwind F, Sereda O, Fromm KM. Multitopic ligand design: a concept for single-source precursors. Inorg Chem. 2009;48(22):10535-47. doi:10.1021/ic9009064.

33. Maudez W, Fromm KM. The heterometallic clusters of trivalent rare earth metals of $\left[\mathrm{Ln}(\mathrm{OPh})_{6}\{\mathrm{Li}(\mathrm{dme})\}_{3}\right]$, with $\mathrm{Ln}_{1 / 4}$ Eu and Sm. Helv Chim Acta. 2009;92(11):2349-56.

34. Gschwind F, Crochet A, Maudez W, Fromm KM. From alkaline earth ion aggregates via transition metal coordination polymer networks towards heterometallic single source precursors for oxidic materials. Chimia. 2010;64(5):299-302. doi:10.2533/chimia.2010.299.

35. Kwon NH, Brog JP, Maharajan S, Crochet A, Fromm KM. Nanomaterials meet Li-ion batteries. Chimia. 2015;69(12):734-6. doi:10.2533/ chimia.2015.734.

36. Crochet A, Brog J-P, Fromm KM. Mixed metal multinuclear $\mathrm{Cr}(\mathrm{III})$ cage compounds and coordination polymers based on unsubstituted phenolate: design, synthesis, mechanism, and properties. Cryst Growth Des. 2016;16(1):189-99. doi:10.1021/acs.cgd.5b01084.

37. Buzzeo MC, labal AH, Long CM, Millar D, Patel S, Pellow MA et al. Homoleptic cobalt and copper phenolate $\mathrm{A}_{2}\left[\mathrm{M}(\mathrm{OAr})_{4}\right]$ compounds: the effect of phenoxide fluorination. Inorg Chem. 2004:43:7709-25.

38. Boyle TJ, Rodriguez MA, Ingersoll D, Headley TJ, Bunge SD, Pedrotty DM, et al. A novel family of structurally characterized lithium cobalt double aryloxides and the nanoparticles and thin films generated therefrom. Chem Mater. 2003;15:3903-12. doi:10.1021/cm020902u.

39. Rothen-Rutishauser BM, Kiama SG, Gehr P. A three-dimensional cellular model of the human respiratory tract to study the interaction with particles. Am J Respir Cell Mol Biol. 2005;32(4):281-9. doi:10.1165/ rcmb.2004-01870C

40. Gwinn M, Vallyathan V. Nanoparticles: health effects-pros and cons. Environ Health Perspect. 2006;114:1818-25.

41. Maynard AD, Robert JA, Butz T, Colvin V, Donaldson K, Oberdörster G, et al. Safe handling of nanotechnology. Nature. 2006;444:267-9.

42. Timbrell J. Biomarkers in toxicology. Toxicology. 1998:129:1-12.

43. Donaldson K, Stone V, Tran C, Kreyling W, Borm P. Nanotoxicology. Occup Environ Med. 2004;61(9):727-8.

44. Li J, Muralikrishnan S, Ng C, Yung L, Bay B. Nanoparticle-induced pulmonary toxicity. Exp Biol Med (Maywood). 2010;235:1025-33.

45. Borm P, Klaessig F, Landry T, Moudgil B, Pauluhn J, Thomas K, et al. Research strategies for safety evaluation of nanomaterials, part $V$ : role of dissolution in biological fate and effects of nanoscale particles. Toxicol Sci. 2006;90(1):23-32

46. Oberdorster G, Stone V, Donaldson K. Toxicology of nanoparticles: a historical perspective. Nanotoxicology. 2007;1:2-25.

47. Brog JP, Crochet $A$, Fromm KM, inventors. Lithium metal aryloxide clusters as starting products for oxide materials patent WO 2012000123 A1; 2011.

48. Shriver DF. The manipulation of air-sensitive Compounds. New York: McGraw-Hill; 1969.

49. Cosier J, Glazer AM. A nitrogen-gas-stream cryostat for general X-ray diffraction studies. J Appl Crystallogr. 1986;19:105-7.

50. Blanc E, Schwarzenbach D, Flack HD. The evaluation of transmission factors and their first derivatives with respect to crystal shape parameters. J Appl Cryst. 1991;24:1035-41.

51. Burla MC, Caliandro R, Camalli M, Carrozzini B, Cascarano GL, Caro LD, et al. SIR2004: an improved tool for crystal structure determination and refinement. J Appl Cryst. 2005:38:381-8.

52. Sheldrick GM. A short history of SHELX. Acta Crystallogr A. 2008;64(Pt 1):112-22. doi:10.1107/S0108767307043930.

53. Spodaryk M, Shcherbakova L, Sameljuk A, Zakaznova-Herzog V, Braem $B$, Holzer $M$, et al. Effect of composition and particle morphology on the electrochemical properties of LaNi 5-based alloy electrodes. J Alloys Compd. 2014;607:32-8

54. Chartouni D, Kuriyama N, Otto A, Güther V, Nützenadel C, Züttel A, et al. Influence of the alloy morphology on the kinetics of AB5-type metal hydride electrodes. J Alloys Compd. 1999:285:292-7.

55. Blank F, Rothen-Rutishauser BM, Schurch S, Gehr P. An optimized in vitro model of the respiratory tract wall to study particle cell interactions. J Aerosol Med Depos Clear Effects Lung. 2006;19(3):392-405. doi:10.1089/ jam.2006.19.392.

56. Maguire T, Novik E. Methods in bioengineering: alternatives to animal testing. Norwood: Artech House; 2010. p. 239-60. ISBN: 9781608070114

57. Steiner S, Mueller L, Popovicheva OB, Raemy DO, Czerwinski J, Comte $P$, et al. Cerium dioxide nanoparticles can interfere with the associated cellular mechanistic response to diesel exhaust exposure. Toxicol Lett. 2012;214(2):218-25

58. Lenz AG, Karg E, Lentner B, Dittrich V, Brandenberger C, Rothen-Rutishauser B, et al. A dose-controlled system for air-liquid interface cell exposure and application to zinc oxide nanoparticles. Part Fibre Toxicol. 2009;6:32-48. doi:10.1186/1743-8977-6-32.

59. Tomašek I, Horwell CJ, Damby DE, Barošová H, Geers C, Petri-Fink A, et al. Combined exposure of diesel exhaust particles and respirable Soufrière Hills volcanic ash causes a (pro-)inflammatory response in an in vitro multicellular epithelial tissue barrier model. Part Fibre Toxicol. 2016;13:67-80. doi:10.1186/s12989-016-0178-9

60. Anson CE, Klopper W. Li J-S, L. Ponikiewski, Rothenberger A. A Close Look at Short $\mathrm{C}-\mathrm{CH} 3$...Potassium Contacts: synthetic and Theoretical Investigations of $\left[\mathrm{M}_{2} \mathrm{CO}_{2}\left(\mu_{3}-\mathrm{OtBu}\right)_{2}\left(\mu_{2}-\mathrm{OtBu}\right)_{4}(\text { thf })_{n}\right](\mathrm{M}=\mathrm{Na}, \mathrm{K}, \mathrm{Rb}$, thf = tetrahydrofuran). Chem Eur J. 2006;12(7):2032-8. doi:10.1002/chem.200500603.

61. Akimoto J, Gotoh Y, Oosawa Y. Synthesis and structure refinement of $\mathrm{LiCoO}_{2}$ single crystals. J Solid State Chem. 1998;141(1):298-302.

62. Maiyalagan T, Jarvis KA, Therese S, Ferreira PJ, Manthiram A. Spinel-type lithium cobalt oxide as a bifunctional electrocatalyst for the oxygen evolution and oxygen reduction reactions. Nat Commun. 2014;5:1-8. doi:10.1038/ncomms4949. 
63. Bard AJ, Faulkner LR. Electrochemical methods: fundamentals and applications. New York: Wiley; 2001.

64. Kwon NH, Yin H, Brodard P, Sugnaux C, Fromm KM. Impact of composite structure and morphology on electronic and ionic conductivity of carbon contained $\mathrm{LiCOO}_{2}$ cathode. Elecrochim Acta. 2014;134:215-21.

65. Borm P, Cassee FR, Oberdorster G. Lung particle overload: old school -new insights? Part Fibre Toxicol. 2015;12:10-4. doi:10.1186/ s12989-015-0086-4

66. Brog J-P, Chanez C-L, Crochet A, Fromm KM. Polymorphism, what it is and how to identify it: a systematic review. RSC Adv. 2013;3(38):16905-31. doi:10.1039/c3ra41559g.

67. Xiao X, Liu X, Wang L, Zhao H, Hu Z, He X, et al. LiCoO 2 nanoplates with exposed (001) planes and high rate capability for lithium-ion batteries. Nano Res. 2012;5(6):395-401. doi:10.1007/s12274-012-0220-7.

68. Kwon NH, Yin H, Vavrova T, Lim JHW, Steiner U, Grobéty B, et al. Nanoparticle shapes of $\mathrm{LiMnPO}_{4}, \mathrm{Li}^{+}$diffusion orientation and diffusion coefficients for high volumetric energy $\mathrm{Li}^{+}$ion cathodes. J Power Sources 2017;342:231-40. doi:10.1016/j.jpowsour.2016.11.111.

69. Kwon NH. The effect of carbon morphology on the $\mathrm{LiCoO}_{2}$ cathode of lithium ion batteries. Solid State Sci. 2013;21:59-65.

70. Lia C-C, Leeb J-T, Loa C-Y, Wu M-S. Effects of PAA-NH $\mathrm{H}_{4}$ addition on the dispersion property of aqueous $\mathrm{LiCOO}_{2}$ Slurries and the cell performance of as-prepared $\mathrm{LiCoO}_{2}$ cathodes. Electrochem SolidState Lett. 2005;8(10):A509-12. doi:10.1149/1.2012287.

\section{Submit your next manuscript to BioMed Central and we will help you at every step:}

- We accept pre-submission inquiries

- Our selector tool helps you to find the most relevant journal

- We provide round the clock customer support

- Convenient online submission

- Thorough peer review

- Inclusion in PubMed and all major indexing services

- Maximum visibility for your research

Submit your manuscript at www.biomedcentral com/submit 